\title{
Mechanical Engineering Note - Safety Analysis of Molten Uranium/Water Interaction in the Uranium Foundry Furnace
}

J. Sze

\section{August 19, 1993}

U.S. Department of Energy

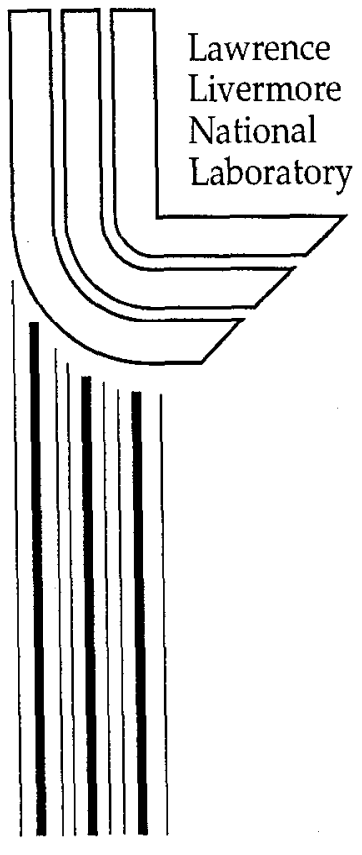




\section{DISCLAIMER}

This document was prepared as an account of work sponsored by an agency of the United States Government. Neither the United States Government nor the University of California nor any of their employees, makes any warranty, express or implied, or assumes any legal liability or responsibility for the accuracy, completeness, or usefulness of any information, apparatus, product, or process disclosed, or represents that its use would not infringe privately owned rights. Reference herein to any specific commercial product, process, or service by trade name, trademark, manufacturer, or otherwise, does not necessarily constitute or imply its endorsement, recommendation, or favoring by the United States Government or the University of California. The views and opinions of authors expressed herein do not necessarily state or reflect those of the United States Government or the University of California, and shall not be used for advertising or product endorsement purposes.

This report has been reproduced directly from the best available copy.

Available to DOE and DOE contractors from the Office of Scientific and Technical Information

P.O. Box 62, Oak Ridge, TN 37831

Prices available from (615) 576-8401, FTS 626-8401

Available to the public from the

National Technical Information Service

U.S. Department of Commerce

5285 Port Royal Rd.,

Springfield, VA 22161 
CODTU-93-0175

ENDT-93-006

AAN93-103557-00

\title{
Mechanical Engineering Note
}

\section{Safety Analysis of Molten Uranium/Water Interaction in the Uranium Foundry Furnace}

\author{
By
}

John Sze

August 19, 1993
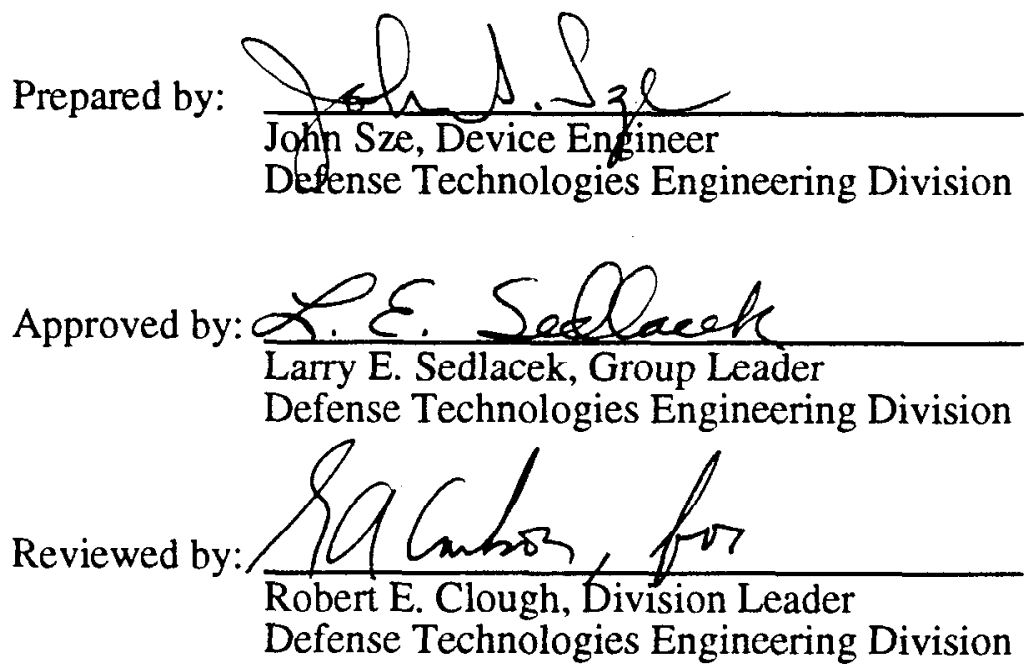

$\mathrm{JS}: \mathrm{pm}$

Distribution:

A. Lingenfelter, L-350

L. Sedlacek, L-122

J. Sze, L-122

R. Clough, L-125

Eng. Information Center, L-127 
CODTU-93-0175

ENDT-93-006

Page 2

\section{TABLE OF CONTENTS}

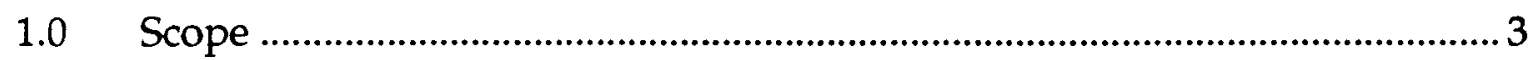

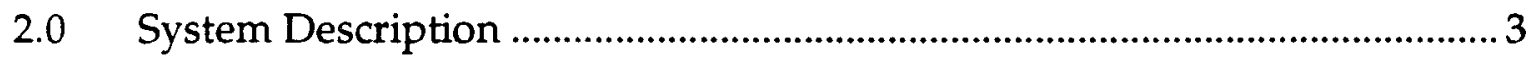

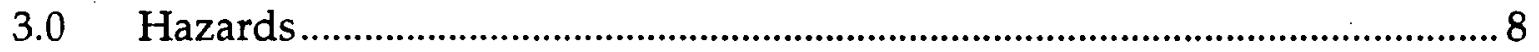

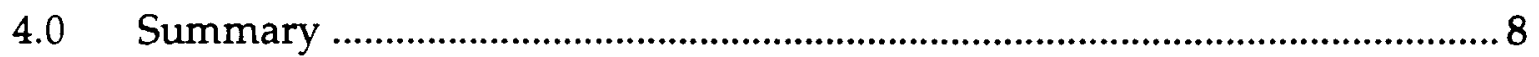

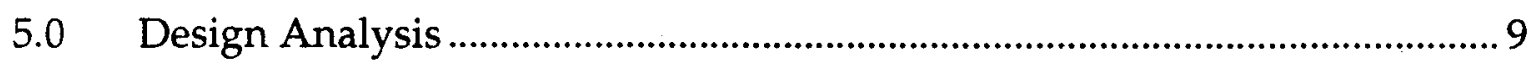

5.1 Molten Uranium/Water Interaction .........................................9

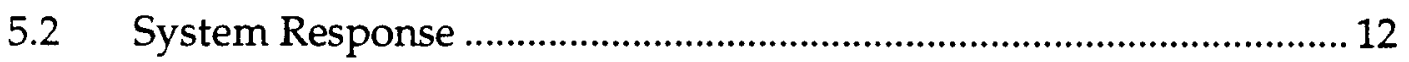

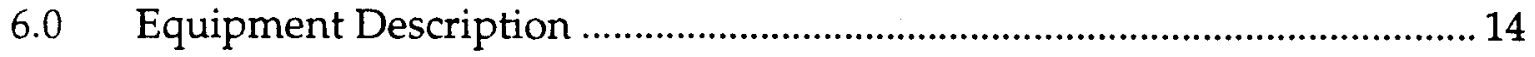

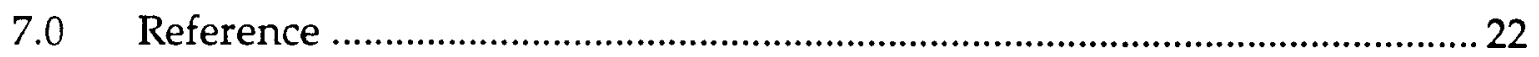

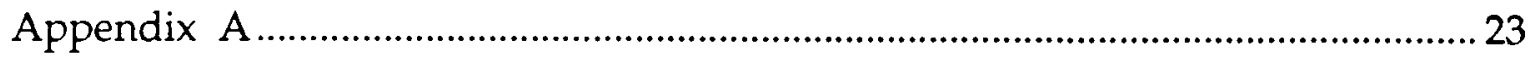

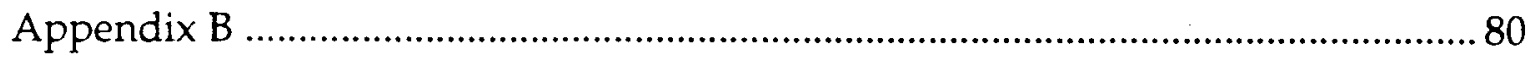


CODTU-93-0175

ENDT-93-006

Page 3

\subsection{Scope}

This Engineering Note describes the development of the accident criteria used the basis for the design of the uranium foundry vacuum vessel. The results of this analysis provide input into other safety notes that investigate how well the uranium containment boundary will maintain its integrity during the design basis accident. The preventative measures that have been designed into the system to minimize the potential to produce a flammable gas mixture are described. The system response is designed for consistency with applicable sections of the LLNL Health and Safety Manual, as well as the Mechanical engineering Safety Design Standards.

\subsection{System Description}

The uranium foundry is located in Building 231, Room 1956A. The floor plan of the foundry is shown in Fig. 1. The vacuum furnace and the assembly hood is shown in Fig. 2. The casting module showing the orientation of the crucible and the mold inside the furnace is shown in Fig. 3. A schematic of the furnace assembly and other equipment in the foundry is illustrated in Fig. 4 and a list of the foundry design parameters is given in Table 1. The vacuum furnace is designed to melt up to $100 \mathrm{~kg}$ of uranium alloy in an induction heated crucible and subsequently drain into an induction heated mold beneath the crucible. There are two induction power supplies in the foundry, one for melting materials and the other for mold heating. The design also includes two water cooling systems. An open loop system is used for chamber wall, power supplies and bus bars cooling and a closed loop system is used for cooling chamber internal hardware. The vacuum furnace and the assembly hood are designed to be vented into a $3000 \mathrm{cfm}$ HEPA filtration negative air system before releasing the exhaust into the atmosphere.

TABLE 1

Uranium Foundry Parameter List

1. Vacuum Vessel

- Chamber Size

- Chamber Material

- Chamber Weight

2. Operating Conditions

- Uranium Charge Capacity

- Uranium Melt temperature

- Mold Temperature

- Crucible Input Power

- Mold Input Power

- Vessel Internal Pressure

- Cooling Water Temperature

- Cooling Water Pressure

- Cooling Water flow
36" x 36" x 60" H (Inside)

1.00" THK. 304 Stainless Steel

Approx. $5000 \mathrm{lbs}$
$100 \mathrm{~kg}$ maximum

$\sim 1500^{\circ} \mathrm{C}$

Approx. $700^{\circ} \mathrm{C}-1000^{\circ} \mathrm{C}$

$100 \mathrm{~kW}$ maximum @ $3 \mathrm{kH}_{\mathrm{Z}}$

$30 \mathrm{~kW}$ maximum @ $50 \mathrm{kH}_{\mathrm{Z}}$

$10^{-6}$ Torr

$50^{\circ} \mathrm{C}$ maximum

45 psig maximum

$25 \mathrm{gpm}$ maximum 


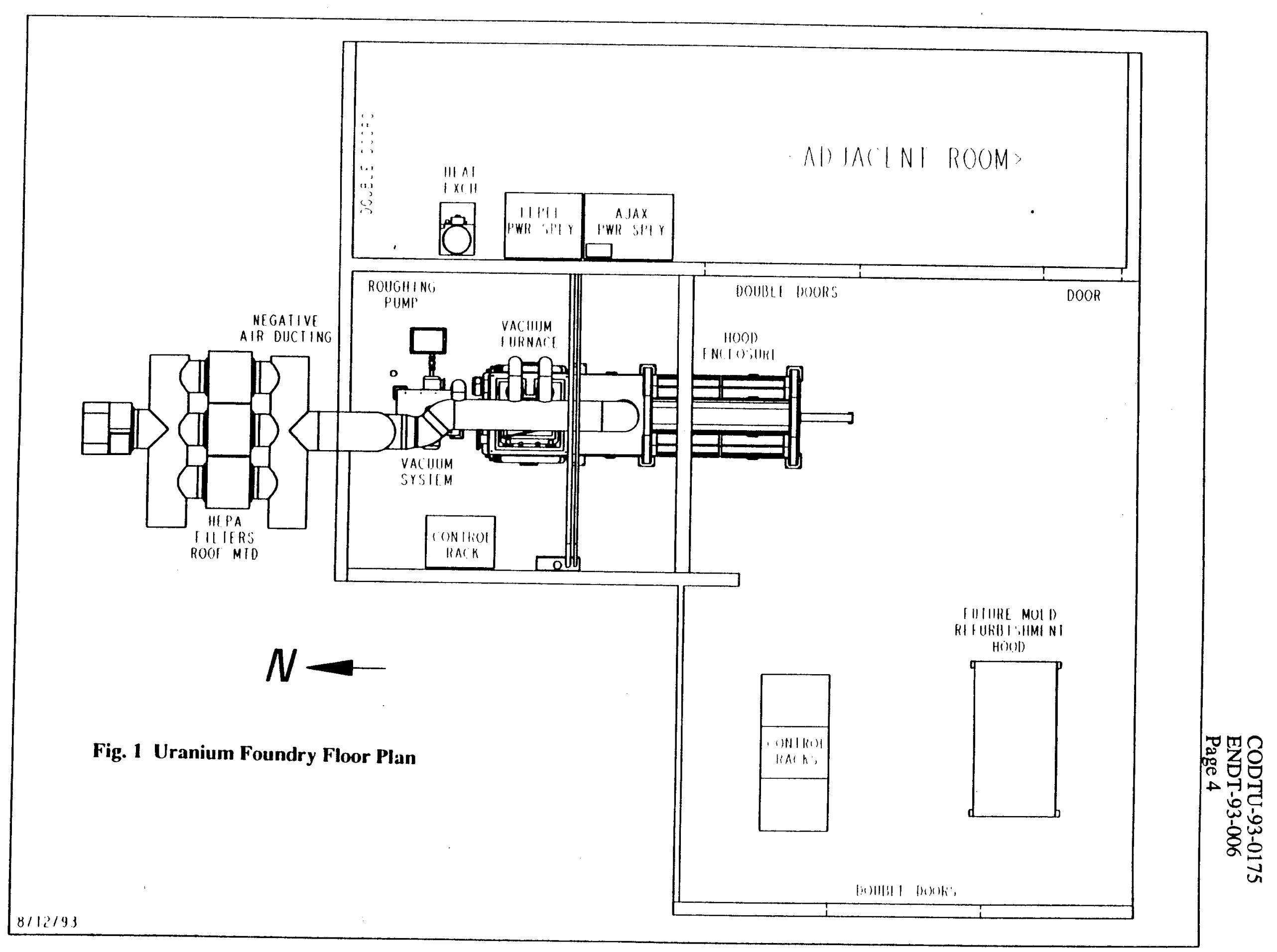





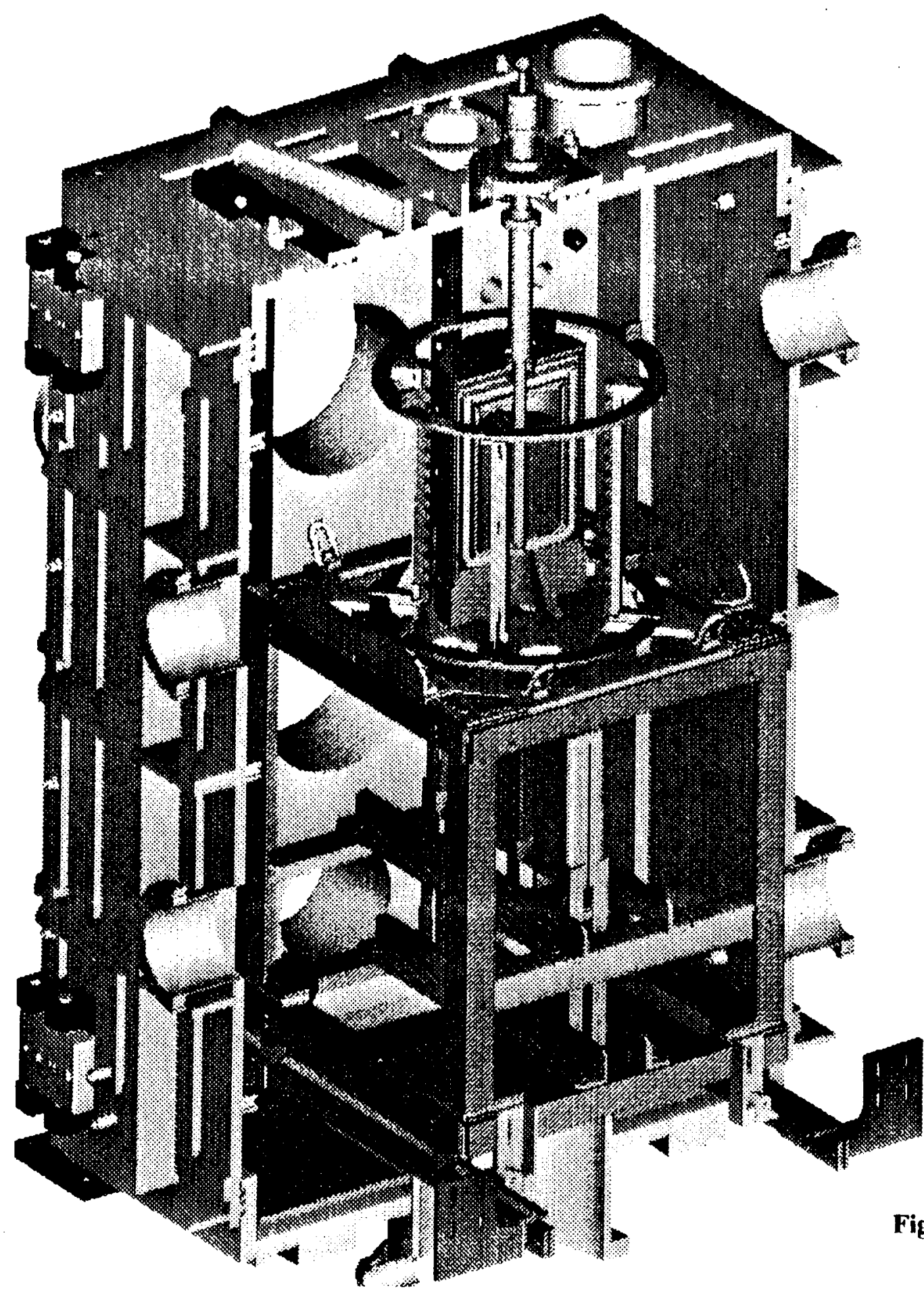

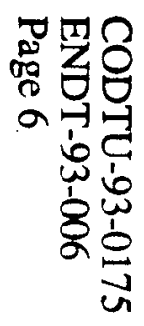

Fig. 3 Casting assembly 


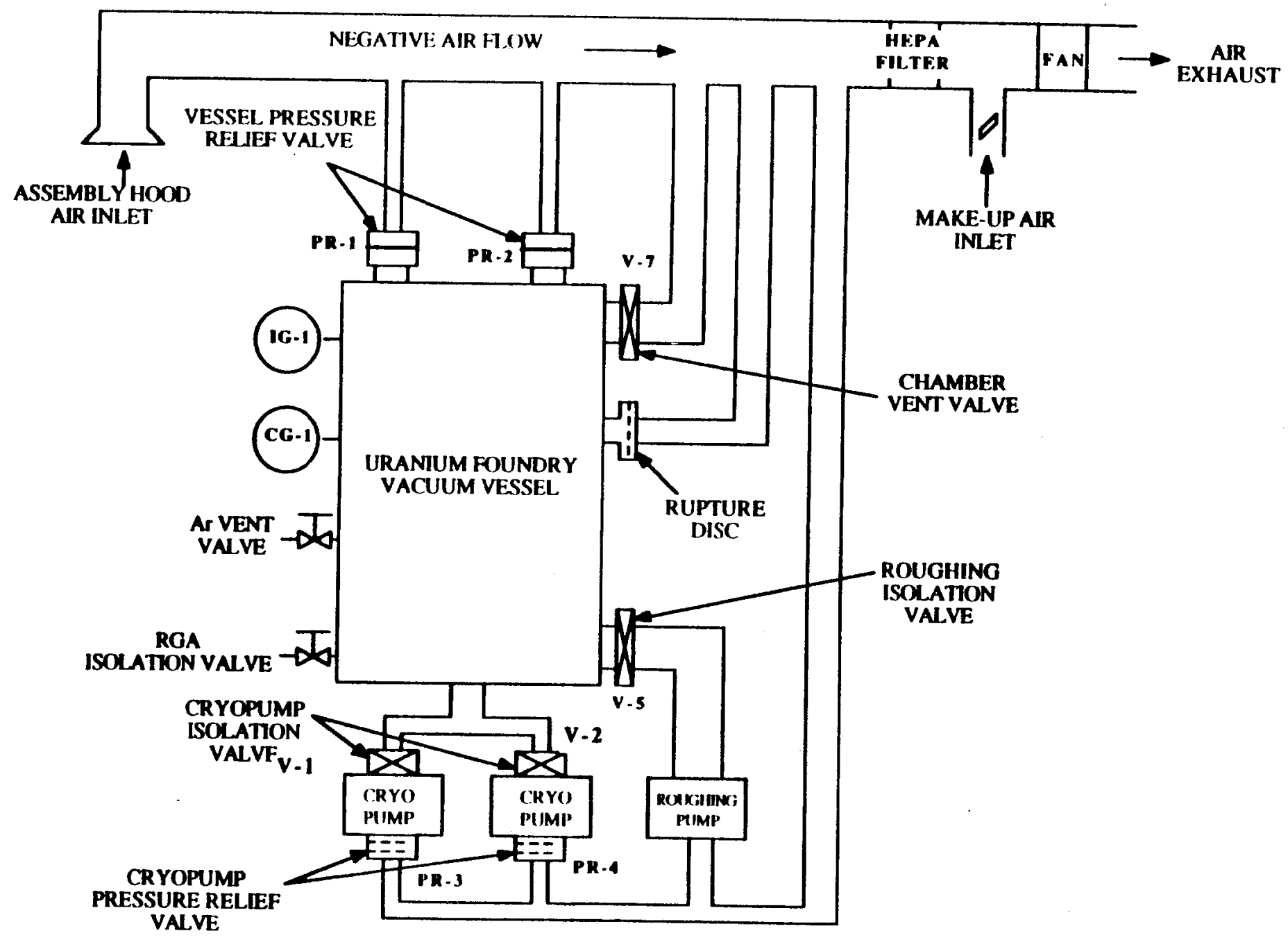

Fig. 4. Schematic of uranium foundry furnace and other equipment 
CODTU-93-0175

ENDT-93-006

Page 8

\subsection{Hazards}

This analysis investigates the following possible hazards associated with molten metal and water interaction in the vacuum vessel.

- Steam generation leading to over pressure

- Hydrogen deflagration

- Damaging steam explosion pressures

- Thermal melt through of vacuum vessel floor

\subsection{Summary}

The safety philosophy in the furnace design is to limit the amount of water available to participate in a molten uranium/water interaction by isolating the coolant flow when an accident condition is detected. The safety analysis (see Appendix A) concluded that hydrogen deflagration and damaging shock pressures resulting from the interaction between molten uranium $\left(-1500^{\circ} \mathrm{C}\right)$ and water can be ruled out due to lack of sufficient premixing between the molten metal and water. The maximum pressure in the vessel from a worst case accident scenario has been calculated to be less than 15 psig over pressure with proper venting capability. This is a conservative estimate because the condensing capability of the vessel wall has been ignored. The vessel is designed to withstand a 15 psig over pressure. Hence, even in the worst case accident condition, the vacuum vessel will not fail.

The primary system response to a water leak inside the vacuum vessel is that the roughing pump isolation valve opens when the vessel pressure rises above the setpoint, pumping steam and hydrogen out of the vessel. The roughing pump remains on during a run and quickly provides a pumping capacity of $3200 \mathrm{cfm}$ to vent the vessel into the negative air duct.

Even if the primary system response fails, the vessel will not pressurize because of the two pressure relief valves and the rupture disc. These two backup systems preserve the structure integrity of the vessel and allow the steam and hydrogen to vent into the negative air duct in a safe manner.

The potential of thermal melt-through due to the accumulation of the molten uranium $(-100 \mathrm{~kg})$ on the vessel floor can be ruled out. The calculation shows that the vessel floor temperature will rise to $\sim 230^{\circ} \mathrm{C}$, it is well below the eutectic temperature for the uranium metal-steel system. 
CODTU-93-0175

ENDT-93-006

Page 9

\subsection{Design Analysis}

The design analysis address two aspects of water leak inside the vacuum vessel: the potential consequences of molten uranium and water interaction, and the system response. The design analysis has been review by an independent consultant, Charles Landram, who is a thermal/fluid specialist in the NTED Division of Mechanical Engineering Department. The Potential consequences of molten uranium and water interaction in this furnace was conducted by Fauske and Associates, Incorporated, The analysis assumes the roughing pump fails to pump hydrogen and steam out of the vessel, resulting in a conservative estimate of the steam and hydrogen generation rates and inventories. The full report is included as Appendix A. The system response to a water leak is described in Section 5.2.

\subsection{Molten Uranium/Water Interaction}

In this analysis there are two accident scenarios leading to molten uranium and water interaction were considered:

1. Rupture of crucible resulting in the melt contacting the water cooled induction coil.

2. Accumulation of water in the mold or chamber floor and subsequent release of molten uranium.

Typically, only one of these systems would be anticipated to fail, but a conservative approach was considered and the key assumptions are summarized below:

a. All of the water coils were assumed to he broken with all the water available in the closed loop system $(\sim 10 \mathrm{gal}$.) spilled onto the vacuum chamber floor.

b. The crucible was assumed to be broken with $100 \mathrm{~kg}$ of molten uranium at $1500^{\circ} \mathrm{C}$ available to burn through a cooling coil or to interact with water accumulated on the chamber floor.

c. Along with the above conditions, the vacuum boundary could be broken and air could enter into the furnace.

d. The vessel volume is $1.27 \mathrm{~m}^{3}$ (i.e. the vessel isolation valves are closed) and the flow area through the pressure relief valves is $0.034 \mathrm{~m}^{2}$. The pressure relief valves are assumed to be the only flow exit, and open when the vessel pressure reaches approximately 1.0 psig.

e. The experimental data developed by the nuclear industry (see Appendix A, Section 3) shows the heat flux for molten uranium dropped into a pool of water could be as high as 10 to $30 \mathrm{MW} / \mathrm{m}^{2}$ for a short time (<10 s). The projected area of the chamber floor was used as the pertinent value for determining the total energy production rate.

f. Maximum steam generation rate was assumed to be limited by the ability of the water droplets to remain as part of the co-dispersed medium.

g. Due to the shallow layers of water $(0.045 \mathrm{~m})$ on the chamber floor not allowing the necessary pre-mixing configuration to be established between the molten uranium and water, Fauske concluded that any energetic steam 
CODTU-93-0175

ENDT-93-006

Page 10

explosive events can be ruled out. Instead a configuration consisting initially of a molten uranium metal layer and a water layer separated by a steam blanket would likely develop.

h. At the lower bound steaming rate $(0.26 \mathrm{~kg} / \mathrm{s})$, there will be sufficient steam inerting taking place in the vacuum vessel for the postulated accident scenarios to eliminate the potential for hydrogen deflagration.

i. The accumulation of the entire uranium inventory of $100 \mathrm{~kg}$ on the chamber floor would not lead to thermal melt through. Charles Landram calculated the vessel floor temperature will rise to $-230^{\circ} \mathrm{C}$, it is always well below the $800^{\circ} \mathrm{C}$ eutectic temperature for the uranium metal-steel system[1].

j. Based on the maximum steaming rate $(11 \mathrm{~kg} / \mathrm{s})$ the relief area of about 0.033 $\mathrm{m}^{2}$ or two 6 inch ports would be adequate without causing the vessel pressure buildup to exceed $15 \mathrm{psig}$. The analysis suggests that the opening pressure for the relief system should be set near ambient pressure $(\sim 1 \mathrm{psig})$ to allow for the maximum time $(\sim 0.1 \mathrm{~s})$ to assure a fully open relief system as the pressure approaches the chamber design pressure of $15 \mathrm{psig}$. If any one of the pressure relief valves malfunction and the vessel reaches pressure $13 \mathrm{psig} \pm 2 \mathrm{psig}$, an 8 inch rupture disc will burst to vent the vessel into the negative air system.

The vessel pressure is shown as a function of time for the worst case scenario (i.e., roughing pump fails) in Fig. 5. The steam pressure builds up because water is in contact with surface temperature well above the boiling point with a steaming rate of $11 \mathrm{~kg} / \mathrm{s}$. Steam generation continues after the relief valves open at its cracking pressure of $\sim 1.0$ psig to vent gas into the negative air duct. The vessel pressure continues to build up and reaches a maximum pressure of $-9.7 \mathrm{psig}$ in about $0.06 \mathrm{~s}$ after the relief valves open. The vessel venting rate increases with the venting area of the relief valve which causes the vessel pressure to decrease. This is a very conservative assumption because the condensing capability of the vessel wall has been ignored and the roughing pump will normally be on during a water leak. Hence the implicit assumption is that the roughing pump fail at the same time the water leak occurs.

k. The cooling coil will not be damaged by direct contact of molten uranium because of the uranium crust formation on the copper surface as concluded by Fauske (see Appendix A, Section 2). This accident scenario was also analyzed by Charles Landram [1] independently with different assumptions and his calculation showed that the copper cooling line is likely to be ruptured by thermal melt-through. Nevertheless, a cooling line failure poses no additional impact with respect to safety issue of the vessel design (see Appendix B). 


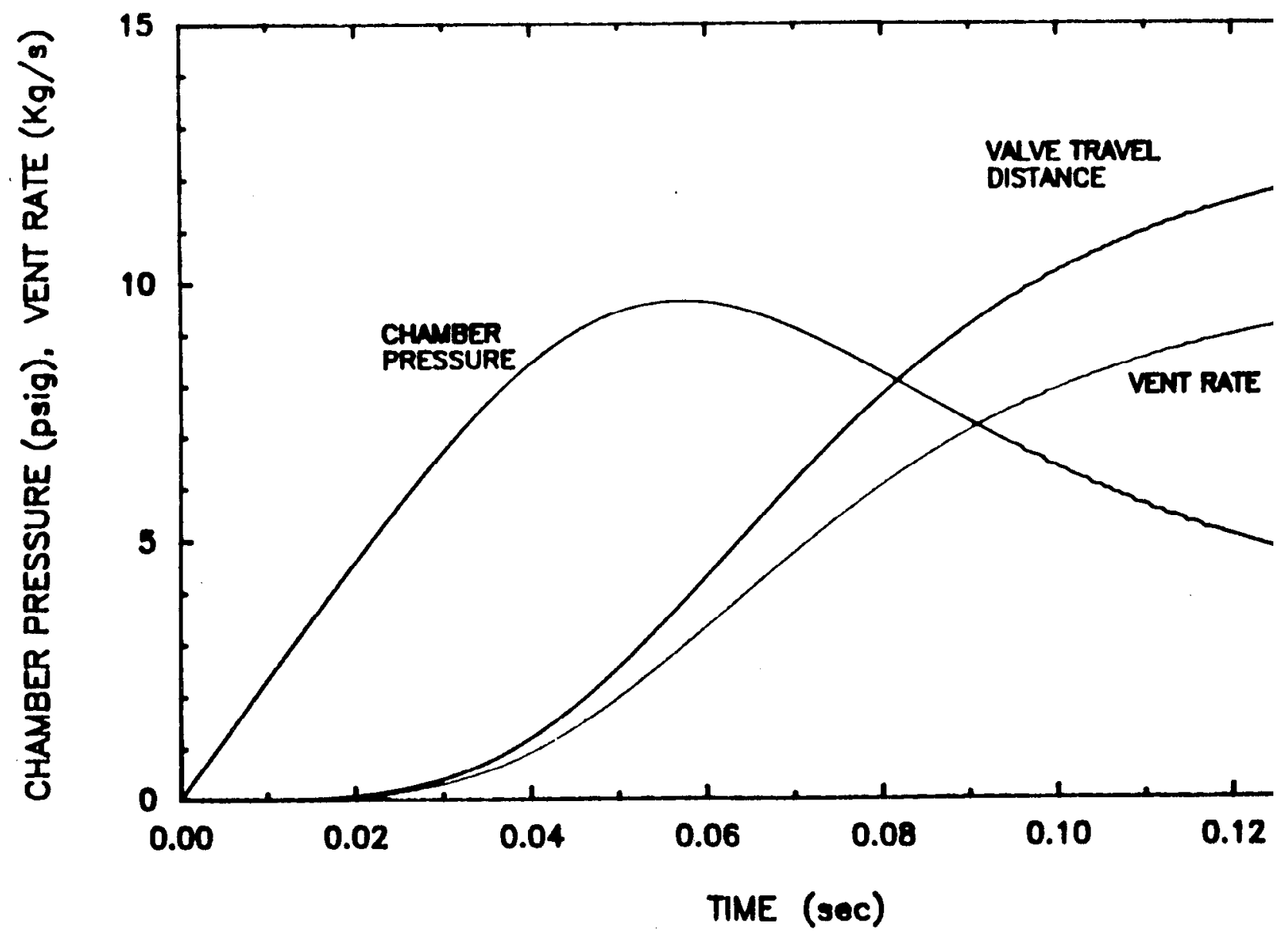

Fig. 5. Calculated chamber pressure relief capability as a function of tim 
CODTU-93-0175

ENDT-93-006

Page 12

\subsection{System Response}

The Primary system response to a water leak occurs inside the vessel and is provided by the operation of the roughing pump, which will maintain a low hydrogen and steam inventory in the vessel. If the primary response is defeated the system has two back up responses. The first back up is to vent the chamber using two pressure relief valves. If either or both of the pressure relief valves malfunction, the second back up is to vent the chamber through a rupture disc. The details of the system response to a chamber over pressure are shown in Fig. 6, and described below.

a. Ion pressure gauge, IG-1 (see Fig. 4), inside the vessel sense a pressure rise from the normal operating pressure of $<10^{-5}$ Torr. If the pressure rises to greater than $6 \times 10^{-4}$ Torr, the control system automatically shuts off the induction power supplies, closes the cryopump isolation valves V-1 and V-2 and sends an alarm to the operator.

b. If the pressure rise sensed by the convectron gauge, CG-1, is below $30 \mathrm{mTorr}$, the operator may reopen the high vacuum isolation valves (V-1 and V-2) in an attempt to continue operation. If the pressure is reduced to $10^{-6}$ Torr range by this action then the induction power supplies can be manually turned back on. If the pressure is not reduced to $10^{-6}$ Torr range, the operator must identify the gas source or terminate the run.

c. If the convectron gauge, CG-1, reports a pressure rise greater than $30 \mathrm{mTorr}$, the control system automatically opens the roughing isolation valve V-5, allowing the roughing system to pump on the vessel. If the pressure stabilizes below $30 \mathrm{~m}$ Torr, then the operator may attempt to cross back over to high vacuum. When the convectron gage senses chamber pressure greater than $1 \mathrm{mTorr}$ the ion gauge shuts off independently of the control system as well as closes the RGA isolation valve to protect equipment and to eliminate a possible ignition source.

d. The roughing pump has a capacity of $3200 \mathrm{cfm}$ and the pump exhaust is connected to the negative air system to prevent the possibility of releasing any contaminant into the atmosphere. The worst case scenario described in Section 5.1 will only occur if the rough pump fail to pump the vessel.

e. If the convectron gauge CG-1 indicates the chamber pressure $\geq 20$ Torr and the flow sensor indicates a decrease of coolant flow below the setpoint, then the system response as if there is a major water leak inside the chamber. The control system then automatically closes both inlet and outlet control valves of that cooling loop to minimize water egress into the chamber and sends an alarm signal to the operator. Water in other cooling loops continues to flow. The objective of this action is to limit the amount of water available to potentially react with molten uranium. If the solenoid valves fail to stop the cooling water, the operator can manually close two ball valves to shutoff the water flow.

Each cooling loop has two water pressure relief valves for redundancy to prevent over pressure in the cooling lines. If the cooling line pressure buildup to $150 \mathrm{psig}$ or $210^{\circ} \mathrm{F}$, the pressure relief valve will vent the line pressure into the closed loop water tank. 
CODTU-93-0175

ENDT-93-006

Page 13

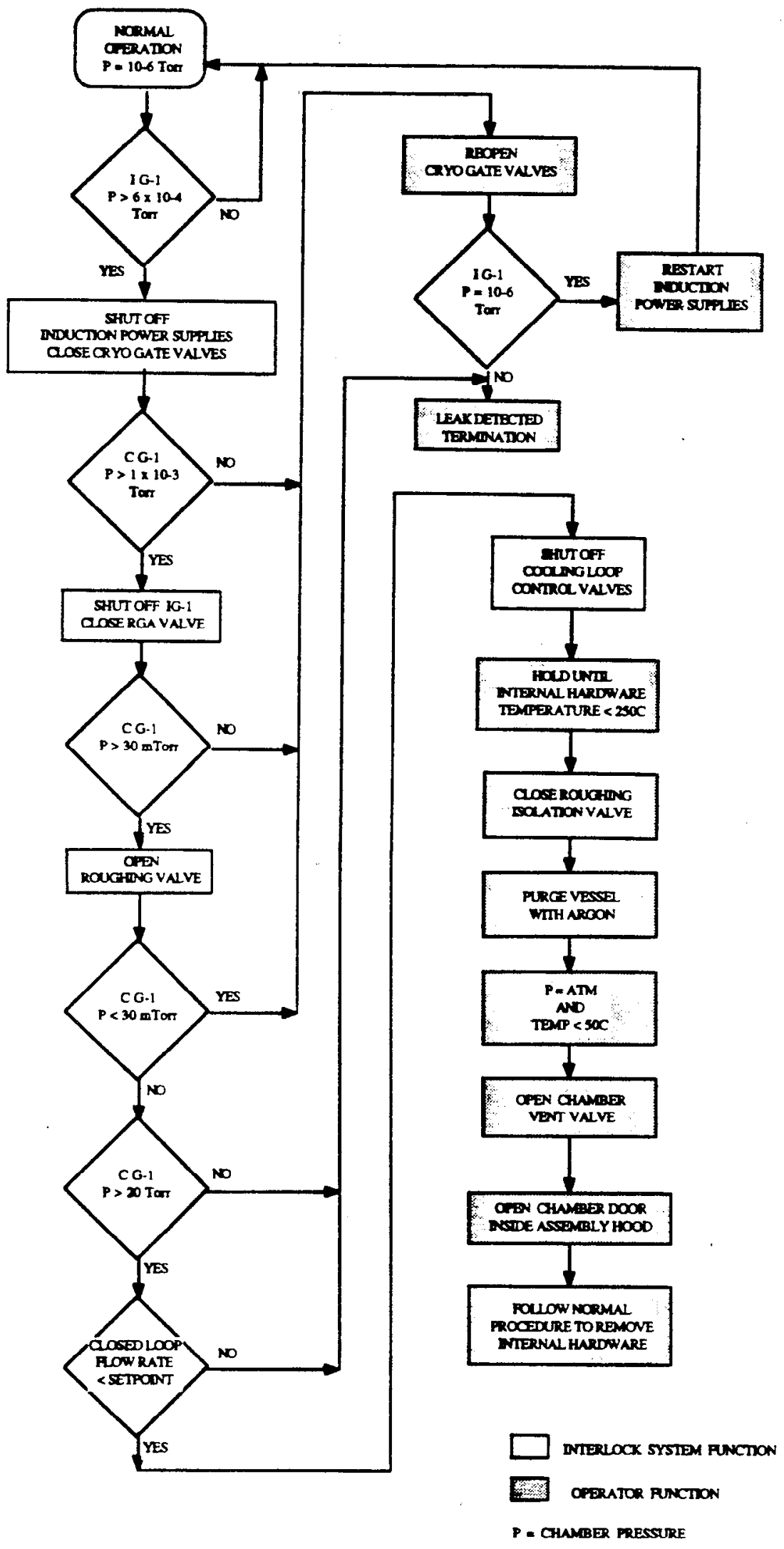

Fig. 6. System response to a water leak flow diagram 
CODTU-93-0175

ENDT-93-006

Page 14

f. After the internal hardware temperature decreases to less than $250^{\circ} \mathrm{C}$, the roughing isolation valve V-5 is closed. Argon gas is available to bleed into the vessel. The argon gas is used to purge the vessel if the roughing pump failed and substantial pressure built up in the vessel while the internal hardware was hot. The argon line has a 3 psig pressure relief device to prevent over pressurization of the vessel during venting.

g. After the internal hardware has cooled to $-50^{\circ} \mathrm{C}$ and the roughing isolation valve is closed, the argon vent valve can be opened by operator command. When the vessel pressure reaches atmospheric, chamber vent valve V-7 is opened to provide flow to the HEPA filters. The chamber door inside the assembly hood can be opened and the internal hardware removed following the usual procedures.

\subsection{Equipment Description}

The equipment described below is designed to satisfy the design analysis.

Roughing Pump: Vessel roughing is provided by an oil-free mechanical pump located inside the experimental area. The pumping capacity is $3200 \mathrm{cfm}$. During normal operation, the roughing pump is used to pump the vessel down to 10 to $50 \mathrm{mTorr}$ range before switching over to high vacuum. The pump is connected to the vessel with a 2 inch vacuum line. The exhaust of the roughing pump is connected to the negative air duct with a 3 inch line.

During a water leak the primary system response to a water leak is to pump hydrogen and steam out of the vessel as it is being generated. The pump will minimize the accumulation of hydrogen inside the vessel, and prevent the vessel from venting into the negative air duct

High Vacuum: A schematic of the vacuum system is shown in Fig. 7. Cross over to the high vacuum pumps occurs when the vessel pressure is reduced to below $30 \mathrm{mT}$ Torr. Isolation valve $\mathrm{V}-5$ is closed, but the roughing pump remains on. Two gate valves $\mathrm{V}-1$ and V-2 are opened and the vessel is pumped down to a pressure below $10^{-6}$ Torr by two cyropumps. The pumping speed and the capacity are listed in Table 2 . However, the pumping capacity of the high vacuum pumps is not a factor in the event of a water leak because the valves to the cyropumps automatically close once the operating pressure is exceeded. The pressure relief vent at the cold head of the cryopump is connected to the negative air duct to eliminate the possibility of releasing hydrogen or contaminant into the experimental area.

TABLE 2

Cryopump CRYO-TORR 8F Specifications

1. Pumping Speed

$\begin{array}{lll}\mathrm{H}_{2} \mathrm{O} & 4000 & 1 / \mathrm{sec} \\ \mathrm{Air} & 1500 & 1 / \mathrm{sec} \\ \text { Argon } & 1200 & 1 / \mathrm{sec} \\ \mathrm{H}_{2} & 2200 & 1 / \mathrm{sec}\end{array}$

2. Pumping Capacity

Argon

Hydrogen at $5 \times 10^{-6}$ Torr

1000 std. liters

8 std. liters 


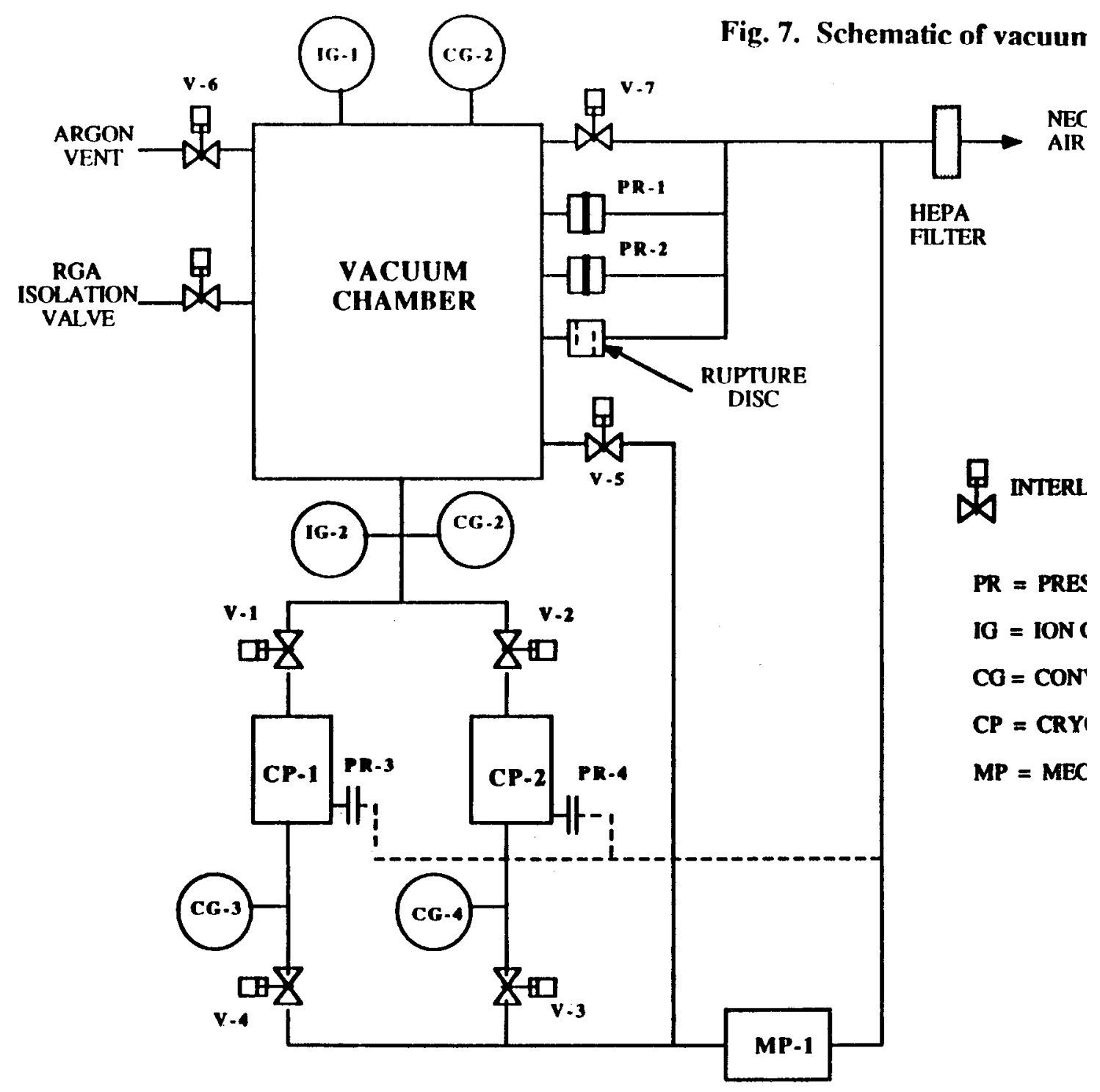


CODTU-93-0175

ENDT-93-006

Page 16

Negative Air: A negative air fan and three HEPA filters provide negative air pressure to the vacuum vessel as well as the assembly hood. The specification drawing of the negative air system is shown in Fig. 8. The capacity of the negative air fan is $-3000 \mathrm{cfm}$. A 14 inch diameter sheet metal duct leads from the vessel and the assembly hood to the HEPA filters on the roof of Building 231. The ducting is rated to be operated at a negative pressure of 7 inch of water $(0.25 \mathrm{psi})$ and the assembly hood is rated to be operated at a negative pressure of 10 inch of water $(0.36 \mathrm{psi})$. A separate control system (see Fig. 9 ) is used to provide negative air flow with face velocity of $125 \mathrm{fpm} \pm 25 \mathrm{fpm}$ at the assembly hood to comply with the LLNL Health \& Safety Standards [4]. The performance of the HEPA filtration system is monitored continuously. Visual and audio warning signals will be given to the operator if the performance of the filtration system drop below the operating setpoint. In the event of the accident scenario as described in section 5.1, the gas flow into the duct is not flammable under any conditions, and hence will not burn the HEPA filters.

Chamber Vent Valve: Under normal operating conditions, a 6 inch chamber vent valve V-7 (see Fig. 10) can be opened by operator command after a casting run. When the chamber pressure reaches atmospheric, the valve is opened to provide flow to the HEPA filters, then the vessel door located inside the assembly hood can be opened. Air may enter into the vessel during the opening of the vessel door and may cause portions of the exposed uranium to oxidize. The reaction rate is controlled by introducing air slowly after the internal hardware has cooled to below $50^{\circ} \mathrm{C}$ and the amount of Argon present inside the vessel.

Pressure Relief Valve: The two 6 inch pressure relief valves PR-1 and PR-2 located on the top of the vessel (see Fig. 10) limit the maximum pressure in the vessel to below 10 psig, depending on the final valve calibration. The relief pressure for these two valves is set at approximately 1.0 psig. These valves vent into the negative air duct, by-passing the chamber vent valve $V-7$ between the negative air duct and the vessel. The pressure relief valve is described in detail in [2].

The pressure relief valves provide the secondary system response to a water leak. If the roughing pump fails, the vessel pressure is limited by the relicf valves. The vessel with all its instrumentation and feed-thrus will be tested to $15 \mathrm{psig}$, which is 1.5 times the expected maximum chamber pressure, to insure containment is maintained.

Rupture Disc: A rupture disc located on the side of the vessel (see Fig. 10) limits the maximum over pressure in the vessel to less than $15 \mathrm{psig}$. The rupture disc provides the second backup system response to a water leak. If both the roughing pump and the pressure relief valve fail, the disc bursts allowing the vessel to vent into the negative air duct by-passing both pressure relief valves and the chamber vent valve. The rupture disc is designed, built and certified by the disc manufacturer to operate in vacuum below $10^{-6}$ Torr and to burst at 13 psig \pm 2 psig.

Cooling Water: There is a single closed loop heat exchanger and pump unit which provides three closed loop water cooling systems inside the vessel (see Fig. 11). One for the crucible induction heating coil, the second for the mold induction heating coil and the third for the active mold temperature control. The closed loop cooling system provides up to $25 \mathrm{gpm}$ at $45 \mathrm{psig}$ to the vessel during normal operation. Since these cooling lines could develop leaks either due to extended use, or as the result of an accident condition, 


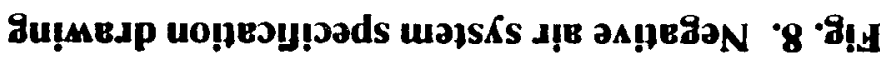

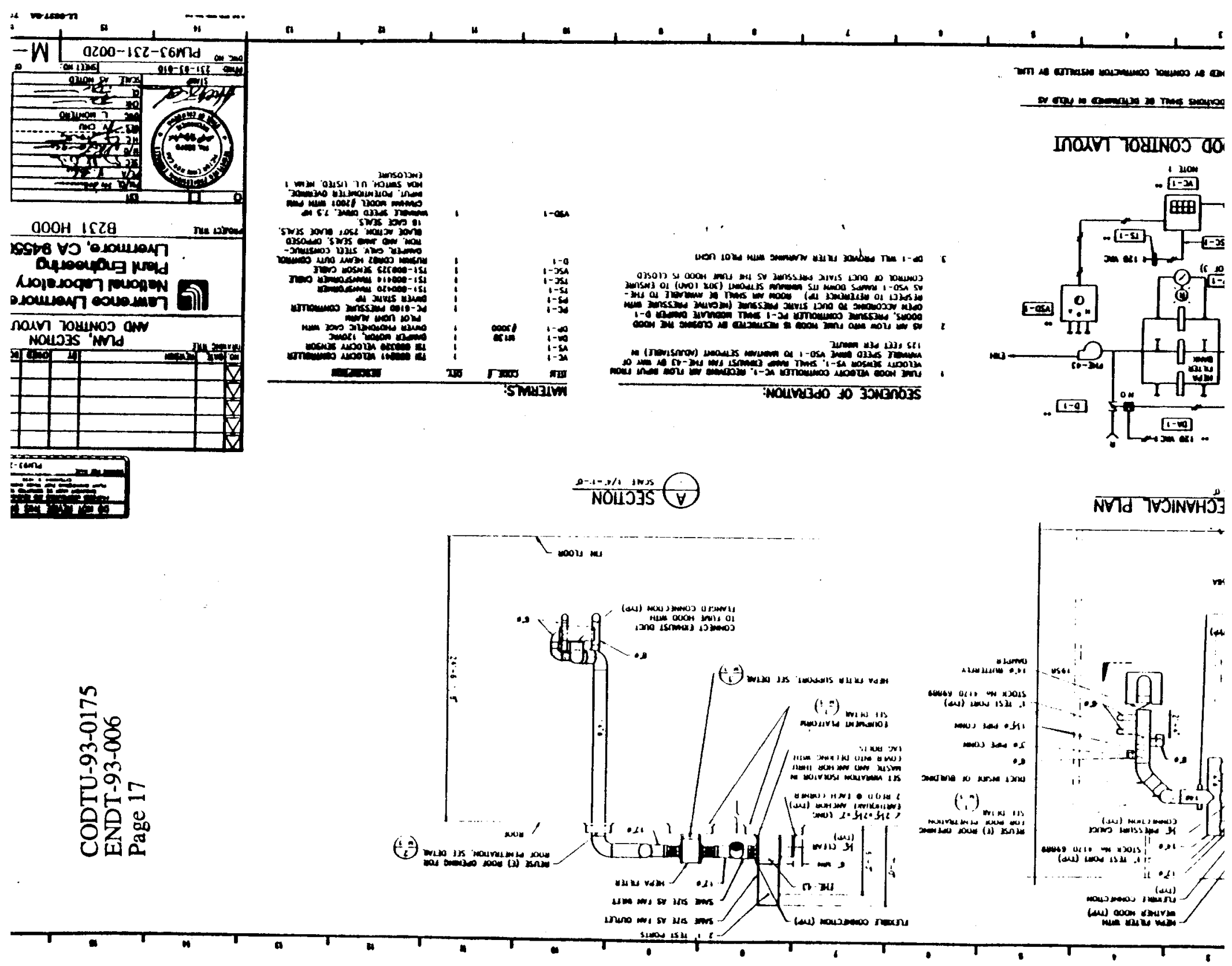




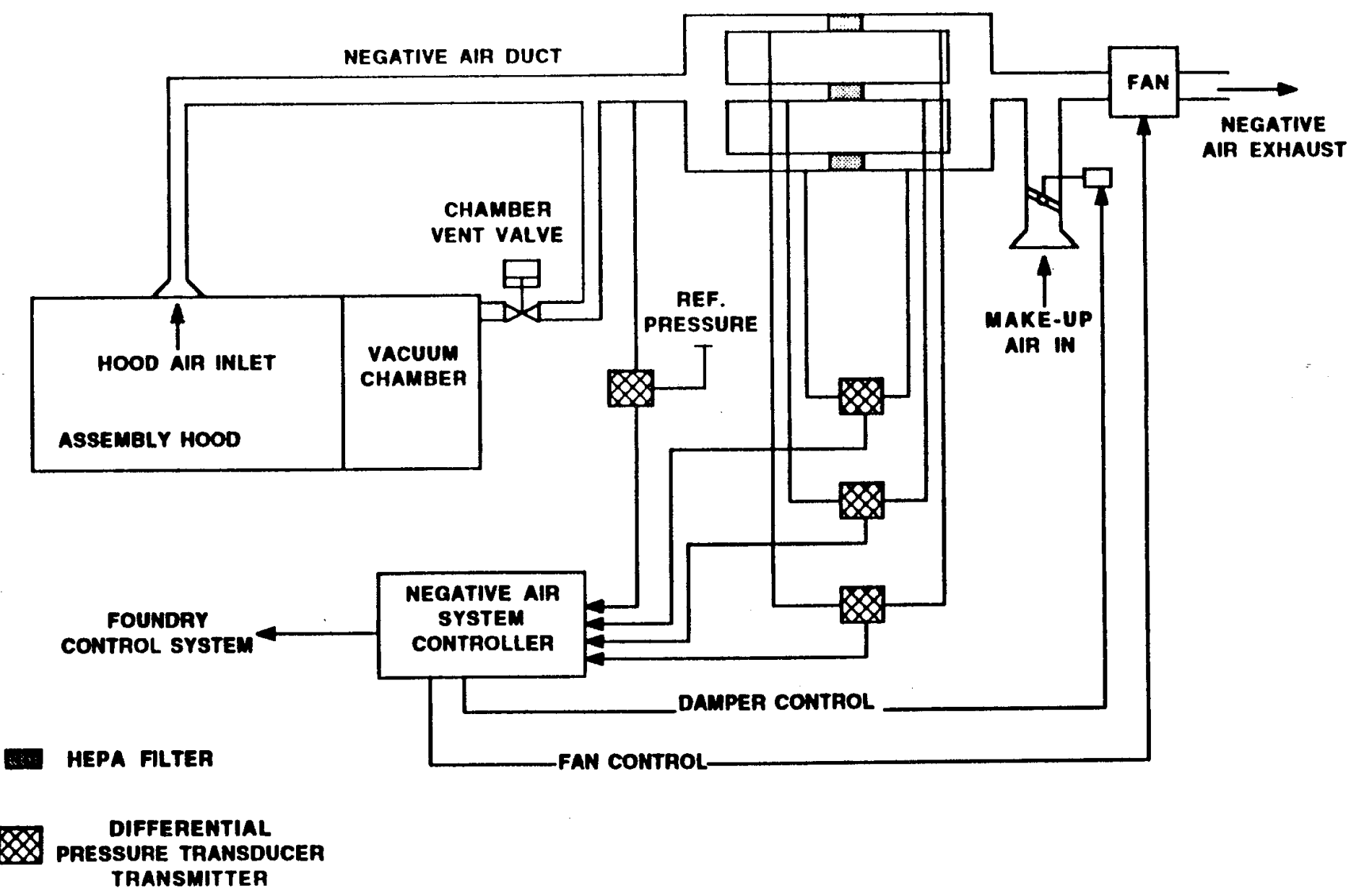

Fig. 9. Schematic of negative air control system 
CODTU-93-0175

ENDT-93-006

Page 19

they are assumed to be the leak source in this analysis. The cooling circuits have building back-up power and switch over to city water automatically in the event of a power failure or the closed loop cooling system failure. The city water is drained into a temporary holding tank for sampling of possible contamination prior to returning to the city drain. Each cooling loop has two pressure relief valves to prevent over pressure as described in Section 5.2. The capacity of the closed loop cooling system water tank is $10 \mathrm{gal}$ and the level is monitored to provide an alarm signal to the operator if the level drops below the operating setpoint. The vessel walls are cooled by traced cooling lines welded to the exterior chamber surface. The cooling circuit for these walls is an open loop system and it is independent of the internal closed loop cooling circuit. 


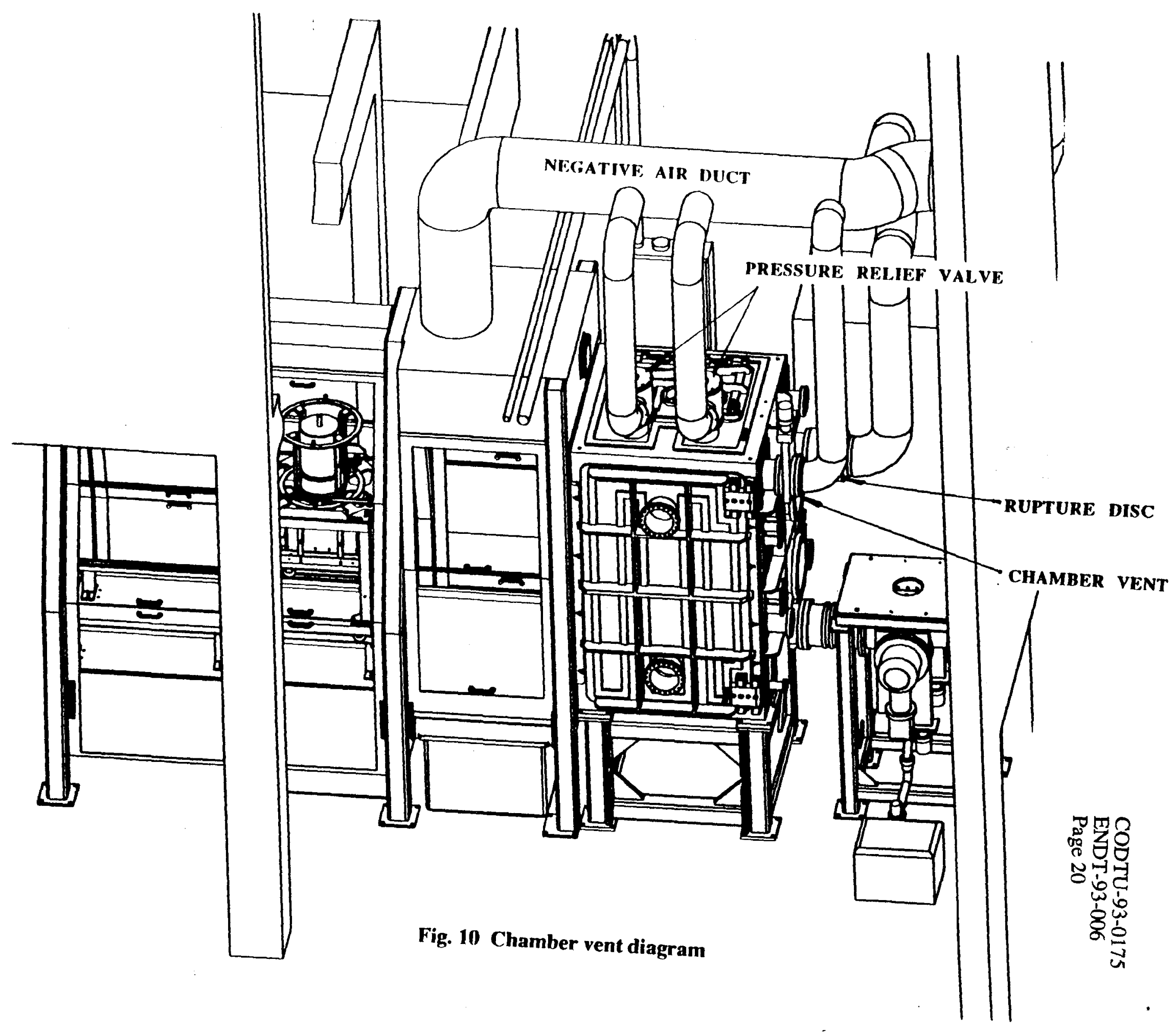




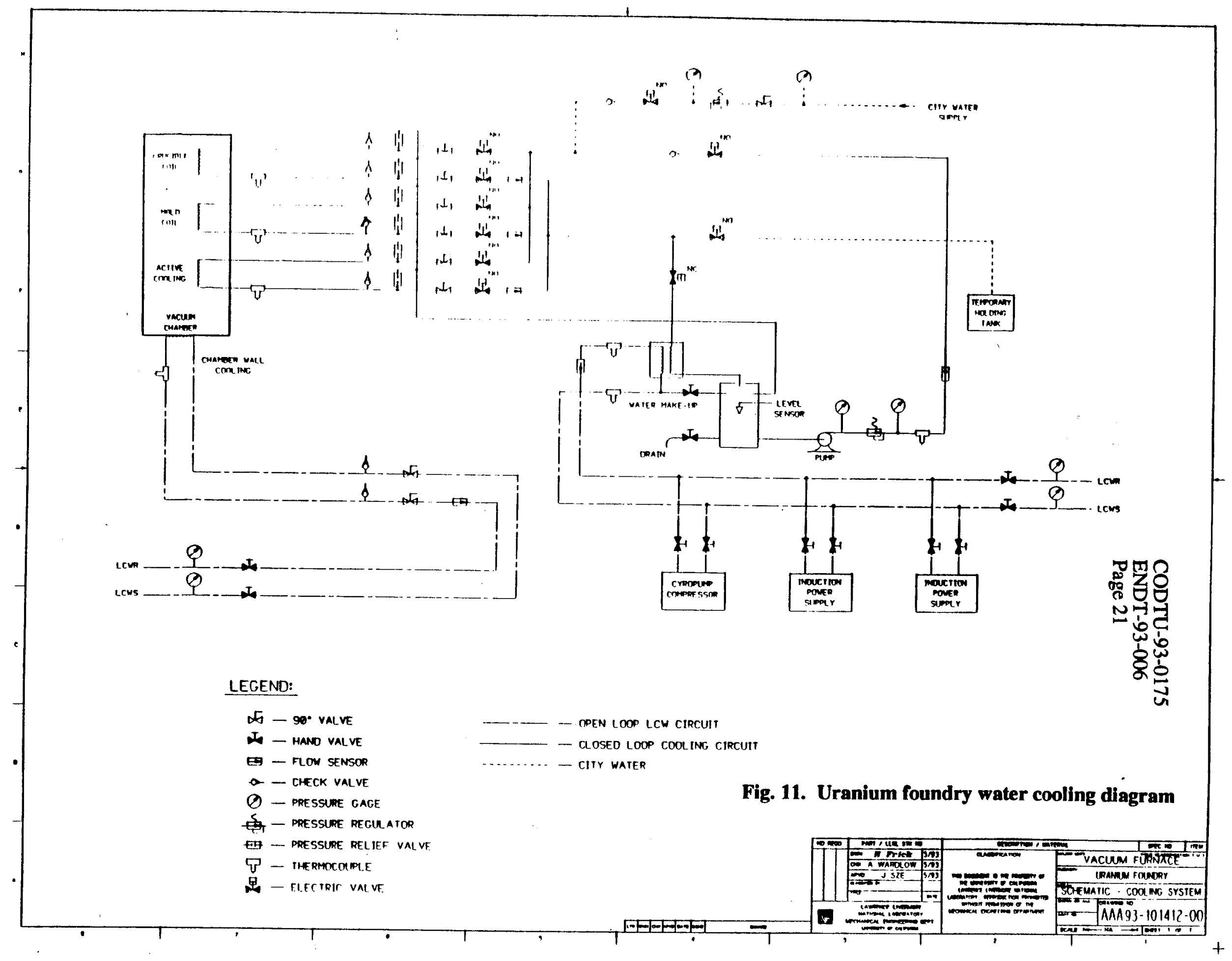


CODTU-93-0175

ENDT-93-006

Page 22

\subsection{Reference}

1. Memo C.S. Landram to J. Sze, "Closure on Fauske \& Associates, Inc., Safety Analysis for the Uranium Vacuum Induction Furnace," TFG93-037, June 29, 1993.

2. "Safety Analysis of Furnace Assembly in the Uranium Foundry," Mechanical Engineering Safety Note, ENDT-93-902.

3. Mechanical Engineering Design Safety Standards, M-012 Rev. 6, Section 3.1 Pressure Vessels and Systems, 1982.

4. "Work Enclosures for Toxic and Radioactive Materials," LLNL Health \& Safety Manual, Supplement 12.03, August 1991. 
CODTU-93-0175

ENDT-93-006

Page 23

\section{Appendix A}

Safety analysis for the Uranium Vacuum Furnace 
CODTU-93-0175

ENDT-93-006

Page 24

FAI/93-35

SAFTIY ARALYSIS FOR THE URANTWY VACUUM IXDOCTIOA FURNACE

Subaitted To:

Layrence Livernore Rational Laboratory Post office Box 808

Livernore, California 94550

\section{Prepared By:}

Pauske \& Associates, Inc. 167070 Dest 83rd Street Burr Ridge, Illinois 60521

June, 1993 
CODTU-93-0175

ENDT-93-006

Page 25

TABLB OF COITHATS

Page

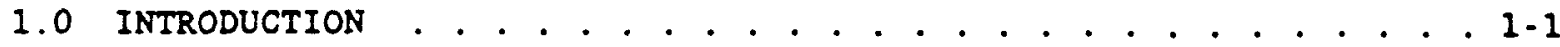

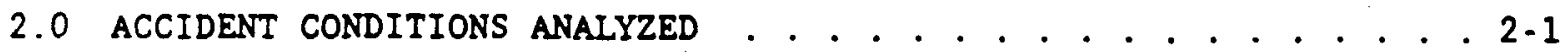

2.1 Description of the Design Analyzed .......... 2-1

2.2 Postulated Accident States for the Safety Analysis . . . . 2-10

3.0 UPDATE OF BASIC CONSIDERATIONS FOR

STEAM EXPLOSIONS AND HYDROGEN BURNS . . . . . . . . . 3-1

3.1 Steam Explosions . . . . . . . . . . . . . 3-1

3.1.1 FAI Thermite Experiments . . . . . . . . 3-2

3.1 .2 Sandia FITSB Tests . . . . . . . . . . . . 3.5

3.1 .3 Summary . . . . . . . . . . . . . . 3-12

3.1.4 Possible Mechanism for Maximum

Steam Generation Rate . . . . . . . . . . . . . 3-13

3.1.5 Shock Waves from Steam Explosions . . . . . . . 3-15

3.1.6 Metal-Water Reactions During

Explosive Interactions ............ 3-18

3.2 Hydrogen Burns . . . . . . . . . . . . . . . . 3.18

4.0 STEAM EXPLOSION EVALUATION ................ . . . . . .

5.0 HYDROGEN BURN EVALUATION ................. . . 5-1

6.0 RELIEF REQUIREMENTS .................. . . . . . .

7.0 OPERATIONAL CONSIDERATIONS ................... . . . .

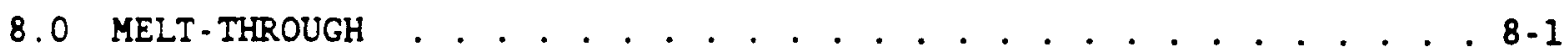

9.0 SUMARY AND CONCLUSIONS ..................... . . . . . .

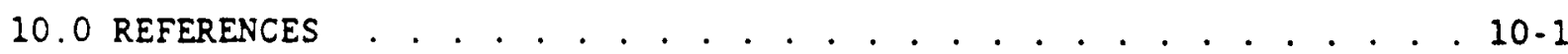


CODTU-93-0175

ENDT-93-006

Page 26

\section{LIST OF FIGORS}

Biqure No.

\section{$2-1$}

$2 \cdot 2$

$2-3$

2-4

$2-5$

$2-6$

$3 \cdot 1$

$3 \cdot 2$

$3-3$

$3-4$

$3-5$

3.6

$3-7$

$3 \cdot 8$

$3-9$

$3-10$

$3 \cdot 11$

Proposed apparatus . . . . . . . . . . . . 2-2

Overall system dinensions.............. 2-3

Proposed furnace enclosure . . . . . . . . . . . 2-4

Melting crucible for the uranium netal ....... 2-5

Position of the crucible . . . . . . . . . 2-6

Relative location of the melt crucible and mold... . 2-7

Measured debris-water energy transfer rates

from EPRI sponsored Mark I Ilner tests . . . . . . . 3-3

FITS containment chamber ........... 3-6

FIIS2B chamber alr pressure .. . . . . . . . 3-9

FITS3B chamber alr pressure . . . . . . . . . . 3-10

FITS6B chamber air pressure (saturated water). . . . . 3-11

Debris dispersion configuration........... . 3-14

Comparison of shock wave pressures for

TNT and point source explosions........... 3-16

Normalized peak pressure $\left(P_{\max } / P_{Q}\right)$ for hydrogen:

air:diluent mixtures, compaling $\mathrm{CO}_{2}$ and steam

(AICC - adiabatic isochoric complete combustion,

$\mathrm{Rh}$ - relative humidity) (Benedick, 1984) . . . . . . 3-20

Hydrogen:air:steam flamability data with

fans off (Marshall, 1986). . . . . . . . . . . . 3-21

Hydrogen:alr:steam flammability data with

fans operational (Marshall, 1986).......... 3-22

Hydrogen:alr:steam flanmability data with fans on and off shown with the exponential curve fit (Marshall, 1986) . . . . . . . . . . . . . 3-24 
CODTU-93-0175

ENDT-93-006

Page 27

\section{HIST OP TABLES}

Table No.

Page

$2-1$

Parameter List for Induction Vacuum Furnace. . . . . 2-8

$3-1$

Effective Heat Flux Measurements

for Debris-Water Interactions ..... . . . . . 3-4

$3-2$

FITSB Initial Conditions and Observations...... 3-7

$3-3$

Chamber Air Pressure Data from FITSB

(Times from Melt Entry).............. 3-17 
CODTU-93-0175

ENDT-93-006

Page 28

\subsection{MiRRODOCTIOA}

The proposed design for the induction vacuum furnace would provide for $100 \mathrm{Kg}$ of molten uranium metal in the induction heated crucible and subsequently drain into the mold beneath the crucible. The design includes three water cooling systems, one for the crucible induction heating coil, the second for the mold induction heating coll and the third for the active cooling in the mold. Since these colls could develop leaks either due to extended use, or as the result of an accident condition, the potential for a melt-water thermal interaction (steam explosion) and the possibility of hydrogen created by steam oxidation of the molten uranium must be considered in the safety analysis. This report describes the design of the furnace used for this evaluation, the postulated accident states considered in the analysis, the basic considerations associated with steam explosions and hydrogen burns, individual evaluations for steam explosions, hydrogen burns and relief requirements, operational considerations which would enhance the safety philosophy, and the potential for melt-through of the molten uranium metal should it spill onto the furnace floor. 
CODTU-93-0175

ENDT-93-006

Page 29

\subsection{ACCIDBST COIDITIOAS ARALYZZP}

\subsection{Description of the Desien Anslyed}

Figures 2-1,2-2 and 2-3 11lustrate the vacuum furnace investigated with respect to the potential for molten uranium-water interactions. Table 2-1 lists the pertinent parameters for the vacuum chamber, the crucible assembly, the mold assembly, the catch basin and the cooling coils. Figure 2-4 shows the crucible used to melt the uranium by induction heating. By withdrawing the stopper rod, the melt drains into the mold below. Figures 2-5 and 2-6 show the orientation of the crucible and the mold assembly.

In these analyses, there are two locations where water and melt could be potentialiy accumulated during an accident where they may come into intimate contact. The first is the mold assembly and the second is the floor of the vacuum furnace. As described in Table 2-1 the inside diameter of the mold is $16 \mathrm{in.}(40.6 \mathrm{~cm})$ which corresponds to an area of $1.40 \mathrm{ft}^{2}$ $\left(0.13 \mathrm{~m}^{2}\right)$ and the floor of the vacuum furnace which is 36 in. by 36 in. $(91.4 \mathrm{~cm}$ by $91.4 \mathrm{~cm})$ or an area of $9 \mathrm{ft}^{2}\left(0.84 \mathrm{~m}^{2}\right)$. These two locations represent the two primary regions where either melt or water could be collected and come into intimate contact. This will be discussed in the following sections.

Item No. 5 of Table 2-1 describes the volume of water avallable in the crucible induction coll, the mold induction coll and the active cooling for the mold. Typically, only one of these systems would be anticipated to fail, but in the following section an end-of-spectrum accident condition will be considered in which all of the water coils will be assumed to be broken with the water inventory spilled onto the floor of the vacuum chamber. The safety philosophy for the furnace is to isolate the coolant flow where any accident condition is detected, which is principaliy indicated by a loss of vacuum. Considering the response time to shut off the cooling water, the maximum arount of water available for reaction inside the chamber will conservatively be taken to be $10 \mathrm{gal}$. (Information provided from John S. Sze to Hans K. Fauske, letter dated June 1, 1993.) 


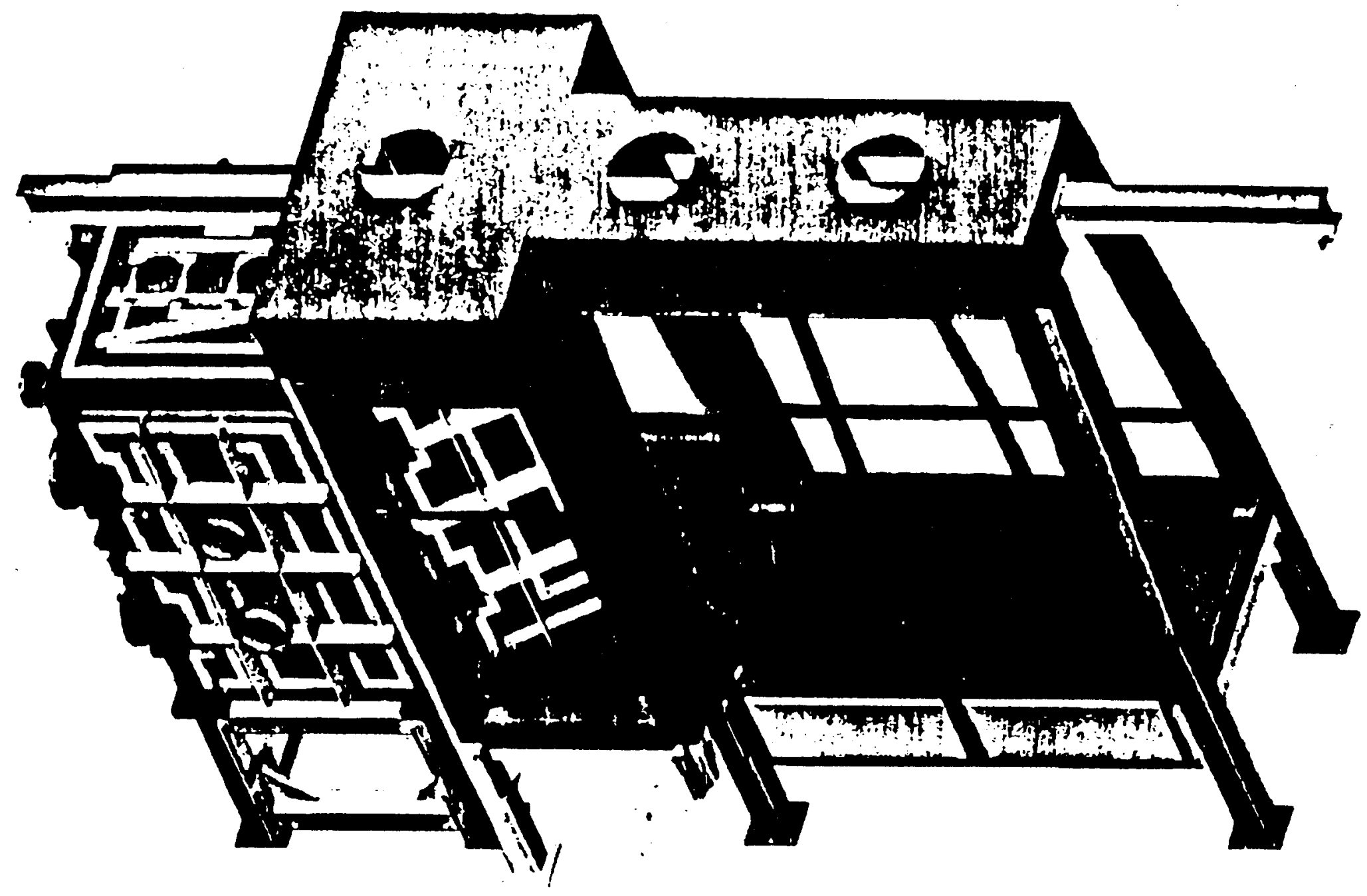

Figure 2-1 Proposed apparatus.

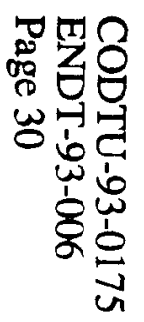




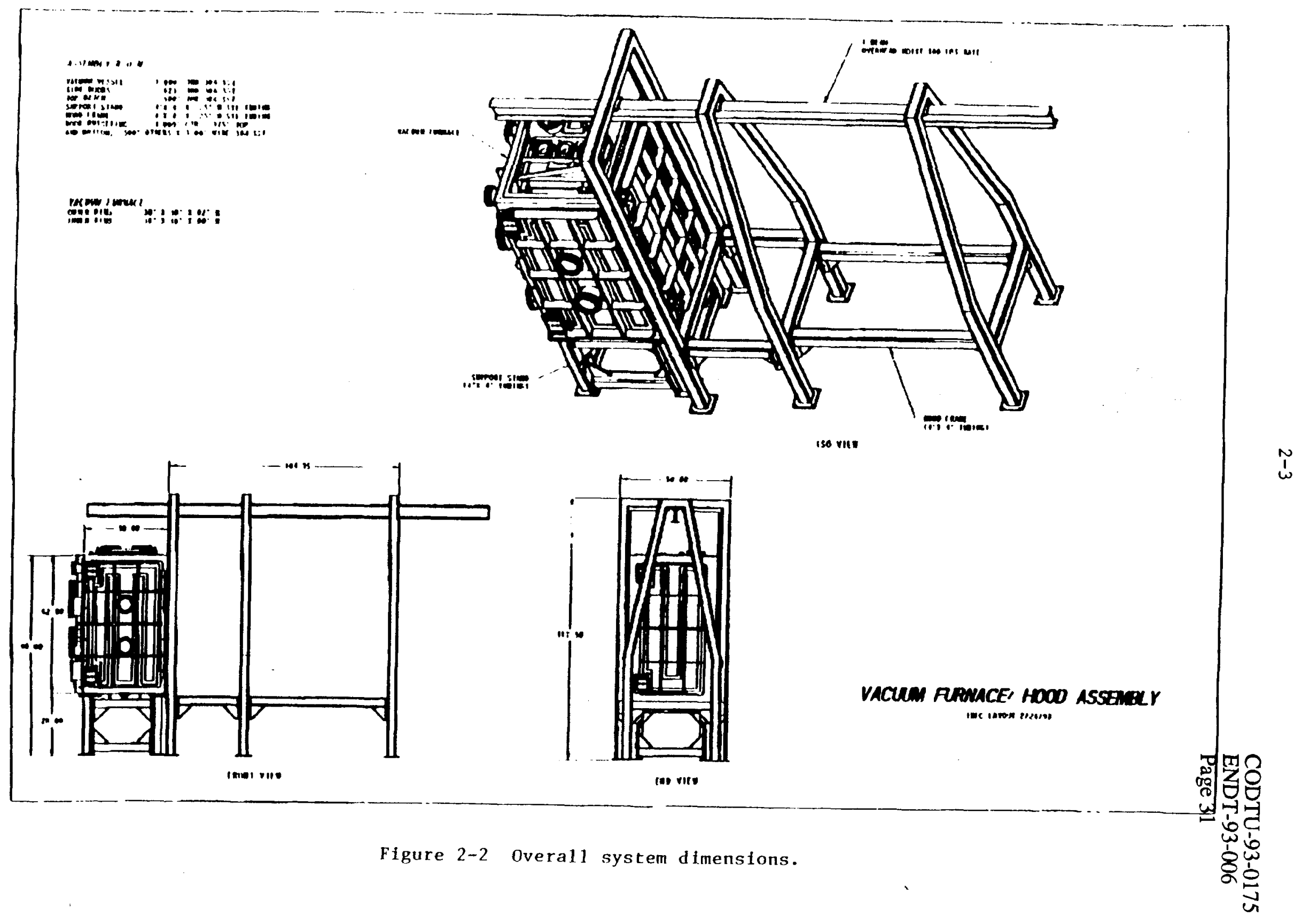




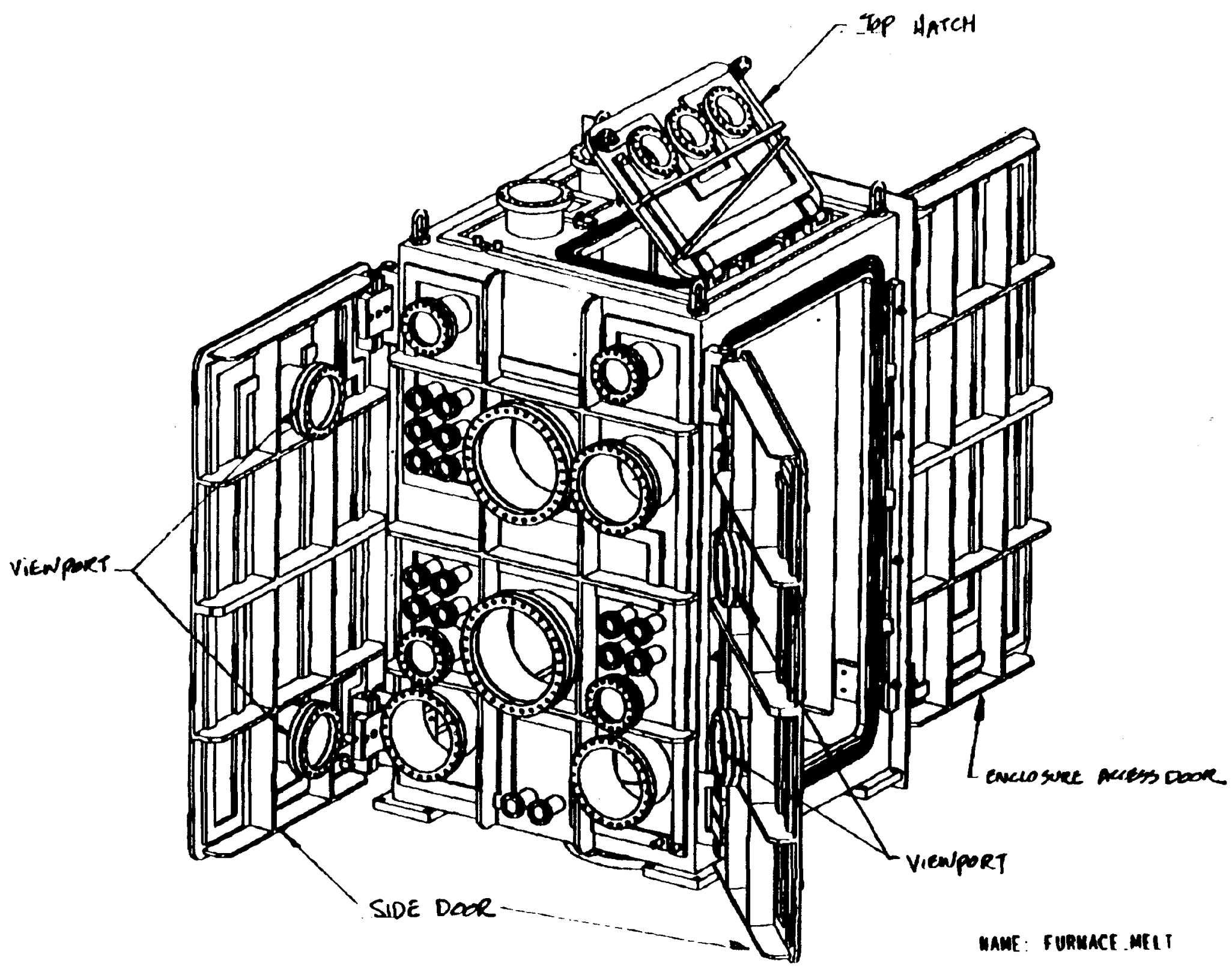

Figure 2-3 Proposed furnace enclosure.

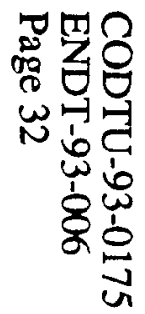




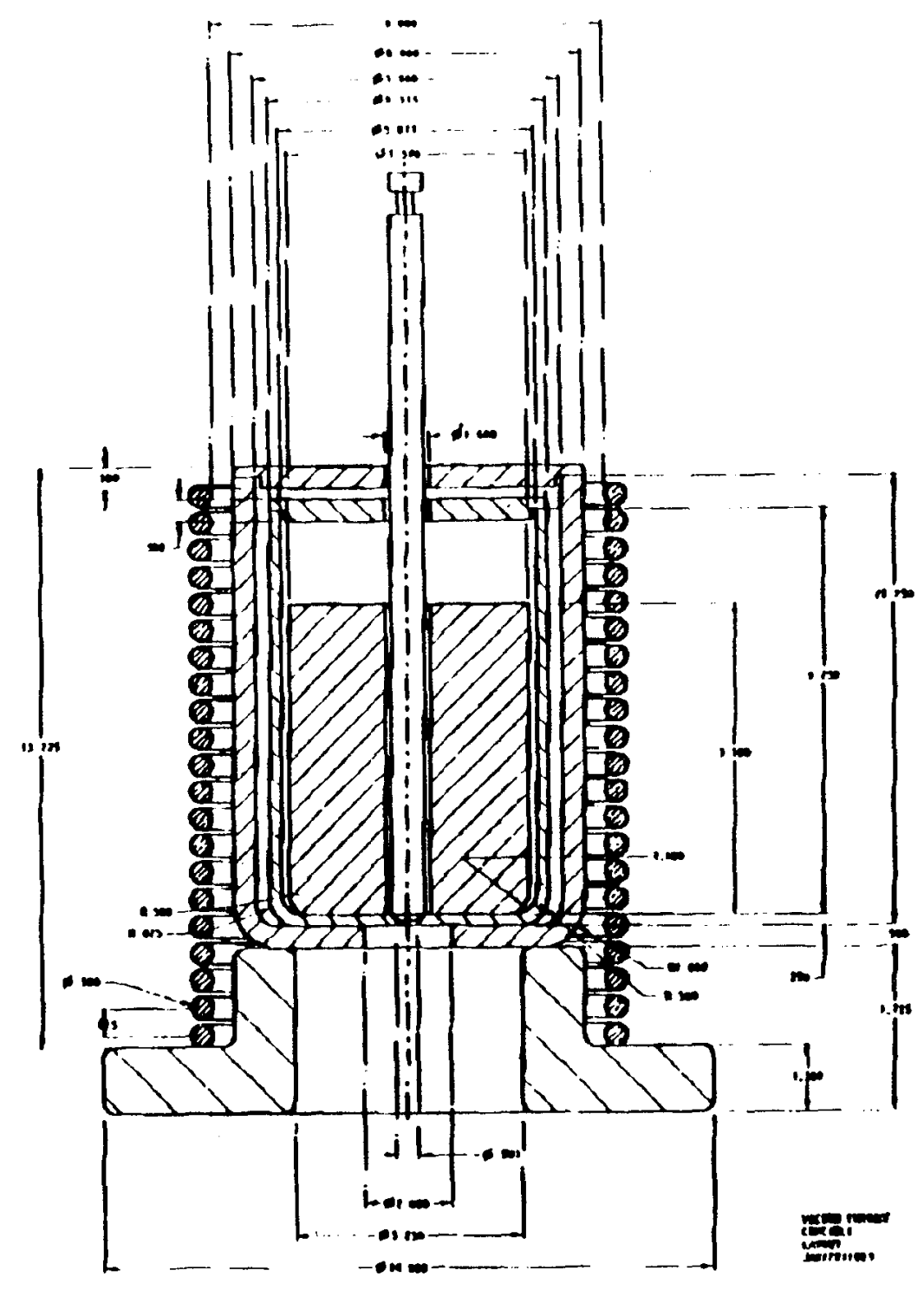

Figure 2-4 Melting crucible for the uranium metal. 
CODTU-93-0175

ENDT-93-006

Page 34

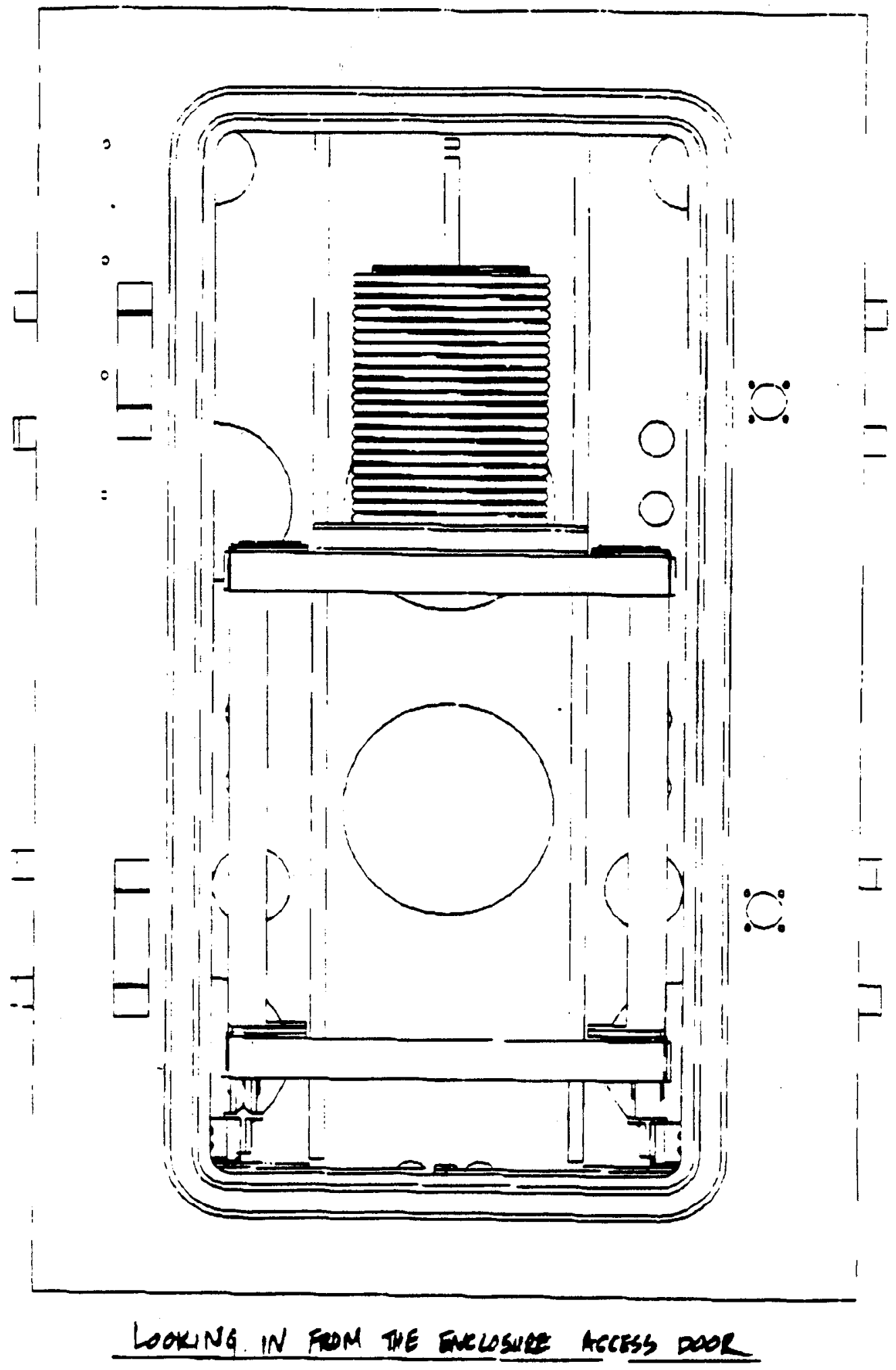

Figure 2-5 Position of the cructble. 
CODTU-93-0175

ENDT-93-006

Page 35

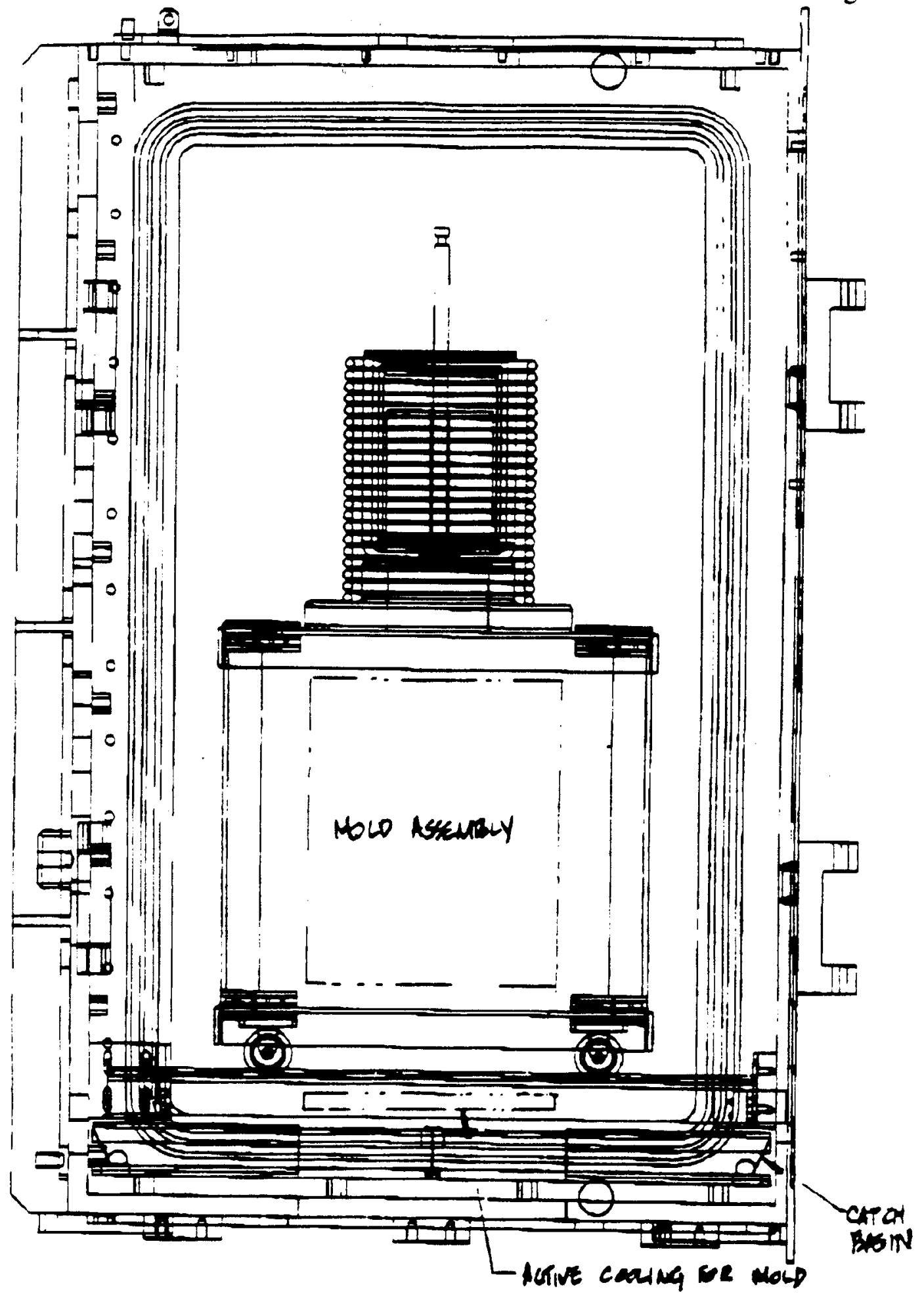

Looking w FERM TWE GIDE DNoR

Figure 2-6 Relative location of the melt crucible and mold. 
Table 2-1

\section{PARAMETER LIST FOR INDUCTION VACUUM FURNACE}

1. Vacuum Chamber

- Chamber Size and Material: Vacuum Vessel

Refer to drawings for detall. $38^{n} \times 38^{n} \times 62^{n} \mathrm{H}$ (Outside)

$36^{n} \times 36^{n} \times 60^{n} \mathrm{H}$ (Inside)

$1.00^{n}$ THK. 304 Stainless Steel

Two Side Doors* $\left(51.5^{n} \times 27.5^{n}\right)$

$.625^{n}$ THK. 304 Stainless Steel

Top Hatch* $\left(21.5^{n} \times 13.5^{n}\right)$

Enclosure Access Door*

$\left(53.5^{n} \times 24^{n}\right)$

$.500 "$ THK. 304 Stainless Steel

$.625^{\prime \prime}$ THK. 304 Stainless Steel

- Operating Pressure

$<10^{-5}$ Torr.

- Support Structure Material

$4^{n} \times 4^{n} \times .25^{n}$ Wall Steel Tubing

- Four Vacuum Viewports

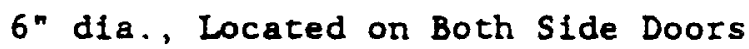

2. Crucible Assembly

- Crucible Size

See attached crucible layout.

- Material

Mullite $\left(\mathrm{Al}_{2} \mathrm{O}_{3}\right)$

- Crucible Lid Material

Mullite $\left(\mathrm{Al}_{2} \mathrm{O}_{3}\right)$

- Stopper Rod

$0.75^{n}$ Dia. $x 15^{n}$ L (Mullite)

- Uranium Charge (D-38)

$100 \mathrm{Kg}$ Maximum

- Operating Temperature

Approx. $1500^{\circ} \mathrm{C}$

- Induction Coll

Oxygen-Free Copper Tubing

- Input Power

$100 \mathrm{~kW}$ maximum

*Double 0-ring sealed door. 
Table 2-1

PARAMETER LIST FOR INDUCTION VACUUM FURNACE

(Continued)

3. Mold Assembly

- Mold Material

- Welght of Mold Materials

- Mold Size

- Operating Temperature Induction Coil

- Input Power

4. Catch Basin *

- Material

- Size

\section{Tantalum}

Approx. $100 \mathrm{Kg}$

Approx. 16" Dia, x 20" L

$800^{\circ} \mathrm{C}-1200^{\circ} \mathrm{C}$

Oxygen-Free Copper Tubing

$20^{n}$ I.D. $\times 22^{n}$ Coil Length

$150 \mathrm{~kW}$ Maximum

$3^{\prime} \times 3^{\prime}$

5. Water Available for Thermal Reaction

- The coolant rates of flow are estimated as follows:

Crucible Induction Coll

Mold Induction Coll

Active Cooling for Mold

$2.5 \mathrm{GPM}$

$9.5 \mathrm{GPM}$

$3.0 \mathrm{GPM}$

- Volume of. water (internal coils and the length to control valves):

Crucible Induction Coil

Mold Induction Coil

Active Cooling for Mold

$80 \mathrm{in}^{3}$

206 in $^{3}$

$80 \mathrm{in}^{3}$

*For the sake of the safety analysis, the water accumulated is to be assumed available to contact molten uranium. However, the catch basin is designed to permit as much as $4 \mathrm{gal}$. to drain without puddling in catch basin. 
CODTU-93-0175

ENDT-93-006

Page 38

\subsection{Postulated Accident States for the Safety Analusis}

Several ways are considered in which molten uranium and water could come into contact. These include:

- rupture of the mullite crucible holding the molten uranium resulting in the melt contacting the water cooled copper induction coll,

- accumulation of water in the mold due to a failure of one or more of the cooling colls and a subsequent release of melt into the mold, and

- accumulation of water on the floor of the furnace and a subsequent release of molten uranium onto the floor of the furnace.

These are ordered in their likelihood of occurrence. While none of these are considered to be frequent occurrences, the potential for a small leak in the mullite crucible which might result in direct contact of molten uranium on the induction coils, is far more likely than a large rupture of coolant lines that could accumulate in elther the mold or the bottom of the furnace. However, the rupture of the mullite crucible and leakage of uranium onto the water cooled copper tubing used for the induction coil should not result in the fallure of the induction coil. The first consideration is the temperature of the coil that would occur if molten uranium, at $1500^{\circ} \mathrm{C}$, were to come into direct contact with the copper coil. The temperature upon contact between the uranium and the copper coil is given by

$$
I_{1}=\frac{I_{U}+T_{C} \sqrt{\frac{k \rho c)_{c}}{k \rho c)_{U}}}}{1+\sqrt{\frac{k \rho c)_{c}}{k \rho c)_{U}}}}
$$

where $I_{U}$ and $T_{C}$ are the respective temperatures of the uranium and copper with $k, p$ and $c$ representing a thermal conductivity, density and specific heat of the copper (subscript c) and uranium (subscript U). Using typical 
values for the properties of uranium metal and copper, the contact temperature between the two materials if the mullite crucible were to rupture is about $400^{\circ} \mathrm{C}$. This is well below the temperature required to freeze the uranium and also well below the copper melting temperature. As a result, it would be expected that the uranium would begin to freeze and form a crust around the fallure location and the copper would not be melted.

Equation (2-1) only describes the interface temperature before the thermal wave penetrates the wall. After this interval the response of the wall is determined by the boundary condition on the coolant (water) side of the tube and the response of the uranium crust formed during the thermal penetration.

Following the inception of crust formation, the thermal penetration of the copper tube wall would be much less than $1 \mathrm{sec}$. and would be followed by nucleate boiling on the inner surface of the copper tube. The heat flux to, and through, the copper tube would then be limited by conduction through the uranium metal crust. Considering this to be given by conduction through the crust with an interface temperature equal to the $400^{\circ} \mathrm{C}$ value calculated above, this results in a heat flux through the copper tubing which is $-6 \mathrm{mw} / \mathrm{m}^{2}$ after $1 \mathrm{sec}$. This is in the range of the critical heat flux for highly subcooled water (Tong, 1965). Consequently, it is anticipated that this rapid transient would not result in any significant potential for dryout on the inner surface of the copper coil and, hence, would not result in any damage to the induction coil. * With the continual flow of water through the cooling coil, it is expected that the energy transfer on the inner side of the copper would be removed by nucleate boiling sufflclent that the copper wall would not overheat and that the flux through the copper wall would be determined by the thickness of the uranium crust frozen on the copper surface. As a result, the uranium crust

*It is noted here that one cannot apply a steady-state boiling curve to assess whether dryout would be induced within an interval comparable to bubble growth and departure times, 1.e. the order of $0.1 \mathrm{sec}$. For this assessment we have used $1 \mathrm{sec}$. as the end of the transient period. 
CODTU-93-0175

ENDT-93-006

Page 40

would continue to grow and the interface temperature would decrease due to sustained nucleate bolling of the water inside the copper tube.

This leaves two other conditions that need to be evaluated, 1.e. accumulation of material within the mold and the accumulation of material on the furnace floor. Accident conditions considered for these two configurations are that one or more coolant lines could be broken due to an external event, such as shaking by a seismic event, with water accumulating in either the mold or the furnace floor. Subsequent to this, the plug could perhaps be also broken or lifted out with welt pouring into the mold. This could cause interaction with the water assumed to be in the mold.

A second consideration would be for the molten uranium to drain onto the furnace floor as a result of the accident condition. Along with these conditions, it is assumed that the vacuum could be broken and air could enter into the furnace. As part of this, the water lines would be isolated and thereby limit the water mass to about 10 gallons. According to the coolant flow rates for the three coils listed in Table 2-1, the accumulation of 10 gallons of water allows about 40 secs.. to shut off the supply of water. 


\subsection{TPRATB OF BASTC COASIDERATIONS POR

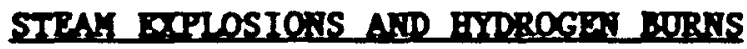

\subsection{Sten Boplosions}

In 1990, two evaluations were performed for the safety assessment of the UDS process vessel; the first evaluated the consequences of steam explosions (FAI, 1990a) and the second considered the influence of hydrogen generation and combustion (FAI, 1990b). The steam explosion evaluation for the UDS vessel included an extensive discussion with respect to basic considerations of vapor explosions including:

- vapor explosion criteria,

- premixing.

- propagation and fine scale mixing, and

- vapor explosion damage potential.

In January of 1993, a CSNI Specialist Meeting on Fuel-Coolant Interactions (steam explosions) was hosted by the University of California at Santa Barbara with the individual papers addressing one or more of these various topics. In sumary, the only potential change to the evaluation provided in 1990 is that detailed computer codes (Fletcher and Denham, 1993; Angelini, et al., 1993) have been developed to evaluate the potential for premixing. These have provided more robust evaluations of the fundamental limitations with respect to premixing. Specifically, these detalled calculations show a rapid depletion of water in the mixing zone as a result of heat transfer from the melt to the water during the premixing stage resulting in hydrodynamic limitations with respect to water remaining in this region. Hence, the only specific update necessary to the 1990 analytical considerations are those related to premixing which further, and more eloquently, evaluate the potential limitations for premixing of a high temperature molten metal and water to initiate an explosive interaction. However, there have been additional experimental results nade avallable that, with interpretation, are useful in these safety evaluations. 


\subsubsection{FAI Therite Rxperinents}

Two sets of experiments have been performed at FAI in which $44 \mathrm{lbm}$ (20 $\mathrm{kg}$ ) of molten iron-thermite was infected into water. The first (Malinovic, et al., 1989) was performed to study the role of water in protecting the Mark I containment liner under severe accident conditions and is discussed extensively in the steam explosion evaluation for the UDS process vessel (FAI, 1990a). The second (Henry, et al., 1991) addressed the influence of water during a high pressure melt ejection. Both of these represent conditions which could cause ex-vessel steam explosions and both facilities were instrumented sufficiently to estimate the steam generation rates resulting from these interactions.

Interpretation of the rate, in terms of a heat flux based upon the projected floor area where the interaction occurs, provide a means of applying the results to another system. Figure 3-1 1llustrates the measured heat flux to the overlying water pool in the Mark I experiments when the test apparatus was instrumented to detect the energy transfer to the test box walls. All tests show a very high energy transfer rate within the first few seconds, the value being between $6.3 \times 10^{6}$ and $9.5 \times 10^{6}$ $B t u / h-f t^{2}\left(20\right.$ and $\left.30 \mathrm{mw} / \mathrm{m}^{2}\right)$, which subsequently decreased to about $0.28 \mathrm{x}$ $10^{B} \mathrm{Btu} / \mathrm{h}-\mathrm{ft} \mathrm{t}^{2}\left(0.9 \mathrm{MW} / \mathrm{m}^{2}\right)$ after the debris is frozen. In this set of experiments, 11 tests were performed, 10 of which had water avallable in the simulated containment prior to the discharge of the molten iron thermite. In all 10 experiments, rapid energy transfer rated $\left(6.3 \times 10^{\circ}-9.5\right.$ $\left.x 10^{\circ} \mathrm{Btu} / \mathrm{h}-\mathrm{ft} \mathrm{t}^{2}\left(20.30 \mathrm{MW} / \mathrm{m}^{2}\right)\right)$ were observed when the debris was discharged into the water.

FAI direct containment heating experiments (Henry, et al., 1991) also had sufficient instrumentation to estimate the steam generation rates when debris was discharged from the simulated RCS into the reactor cavity and subsequently up onto the containment floor. Table 3-1 sumarizes the information for these experiments in terms of the energy transfer rate in the cavity for the three experiments in which water was avallable (DCH-1, $\mathrm{DCH}-2$, and $\mathrm{DCH}-4$ ) and also for the energy transfer rates from the debris to the water as the debris was discharged onto the containment floor. Values 


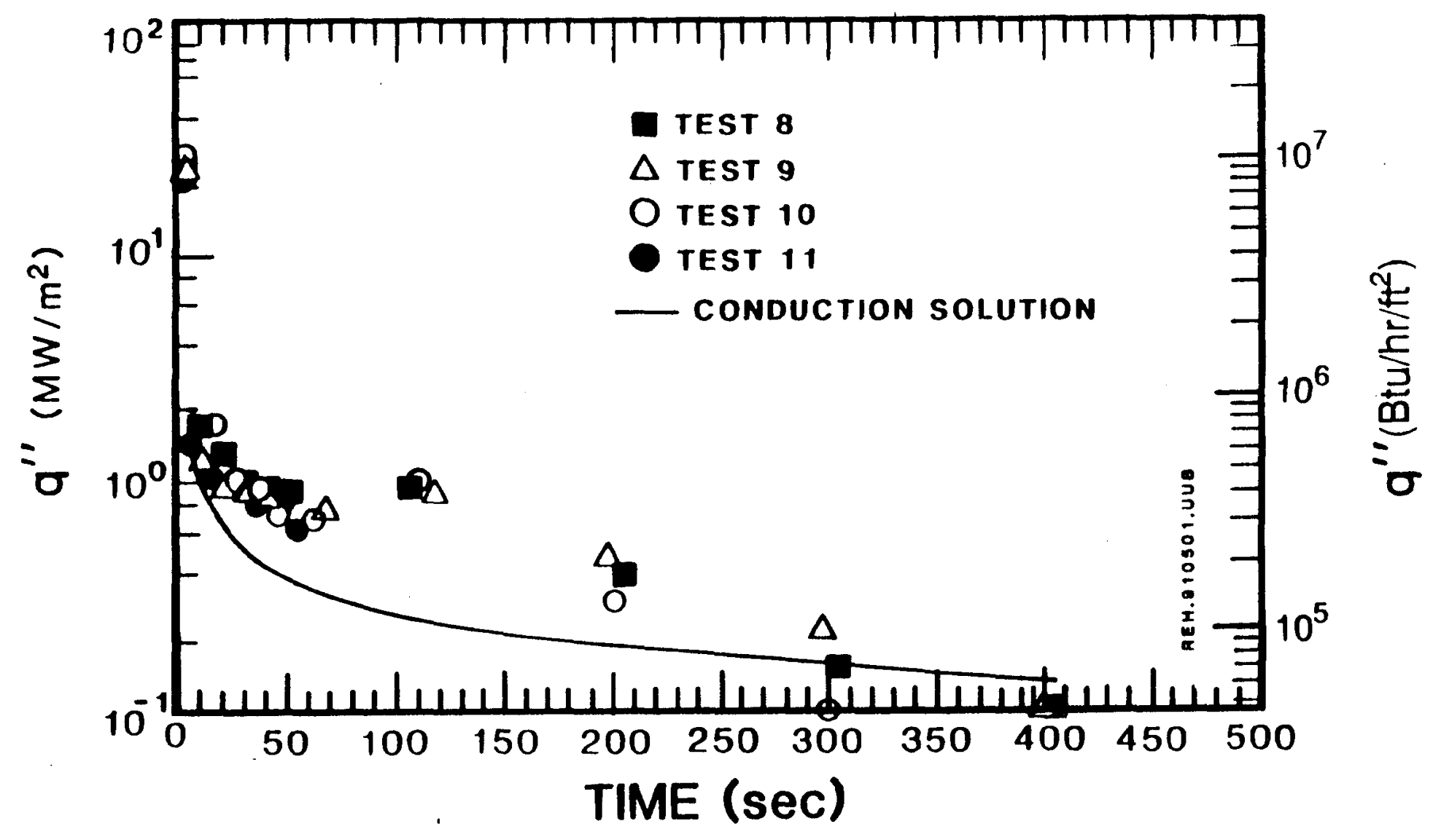

Figure 3-1 Measured debris-water energy transfer rates

from EPRI sponsored Mark I 1 iner tests. 
CODTU-93-0175

ENDT-93-006

Page 44

Table $3-1$

EFFECTIVE HEAT FLUX MEASUREMENTS FOR DEBRIS-WATER INTERACTIONS

\begin{tabular}{|c|c|c|c|c|c|c|}
\hline \multirow[t]{2}{*}{ Test } & \multicolumn{2}{|c|}{$\begin{array}{c}\text { Initial } \\
\text { Pressurization }\end{array}$} & \multicolumn{2}{|c|}{$\begin{array}{l}\text { Intermediate } \\
\text { Period }\end{array}$} & \multicolumn{2}{|c|}{$\begin{array}{l}\text { Long Term } \\
\text { Oygenching }\end{array}$} \\
\hline & $M B \pi L b-f^{2}$ & $\mathrm{MW} / \mathrm{m}^{2}$ & $M B t u / b-f^{2}$ & $M W / m^{2}$ & $M B t w / b-f^{2}$ & $\mathbf{M W} / \mathbf{m}^{2}$ \\
\hline $\mathrm{DCH}-1$ & $4.75 / 13.3^{\circ}$ & $15 / 42^{\circ}$ & $3.49 / 6.02^{\circ}$ & $11 / 19^{\circ}$ & $2.75 / 5.5^{\circ}$ & $8.5 / 17.5^{\circ}$ \\
\hline $\mathrm{DCH}-2$ & $2.22 / 10.78$ & $7 / 34^{\circ}$ & $4.12 / 6.66^{\circ}$ & $13 / 21^{\circ}$ & $2.31 / 5.1 T^{*}$ & $7.3 / 16.3^{\circ}$ \\
\hline DCH -3 & N/A & N/A & N/A & N/A & $1.27 / 4.12^{\circ}$ & $4 / 13^{\circ}$ \\
\hline $\mathrm{DCH}-4$ & $1.27 / 9.83^{\circ}$ & $4 / 31^{\circ}$ & $3.4916 .02^{\circ}$ & $11 / 19^{\circ}$ & $N / A / 2.85^{\circ}$ & $N / A / 9^{\circ}$ \\
\hline
\end{tabular}

"Contribution from the heat sinks added to the vaporization calculation. 
CODTU-93-0175

ENDT-93-006

Page 45

are also given for estimated additional energy transfer due to the transfer into the steel structural heat sinks in the simulated containment lower compartment. These additional energy transfer rates should be sumed with those determined from the containment compartment pressurization rates. As illustrated by this table, the energy transfer rates are large and comparable to those observed in the Mark I tests. These rates are an order of magnitude greater than those typical of the critical heat flux (CHF) for a horizontal upward facing surface.

\subsubsection{Sandia FITSB Tests}

Later Sandia FITS tests have provided sufficient pressure transient information to evaluate the average steam generation rate resulting from explosive interactions. Steam generation rates can then be divided by the cross-sectional area of the FITS vessel to determine the effective heat fluxes. Figure 3.2 taken from (Mitchell, et al., 1986) shows a crosssection of the FITS facility. In this test series, about $18.6 \mathrm{~kg}$ (41 $1 \mathrm{bm})$ of molten thermite was poured into water test containers located in the FIIS chamber and the resultant pressure history in the chamber gas space was recorded. Table 3-2, which was also taken from (Mitchell, et al., 1986), sumarizes the test condftions and observations made with respect to explosive interactions. Figures 3-3 through 3-5 illustrate the pressurization of the gas space, the first two with initially subcooled water and the last with saturated water.

While only some of the experiments had explosive interactions, the principal focus is on the net steam generation rate created by the explosive interaction. The large steel vessel is considered to be pressurized with steam with the realization that this also increases the potential for condensation on the vessel walls. The results shown in Figures 3-3 through 3-5 are those with the largest vessel pressurization. A comparison of these figures also shows that the time to the peak pressure is - $1 \mathrm{sec}$. for these tests, even though the path to this pressure may differ somewhat. (Test FITS 7B experienced about 908 of the pressure increase in the first second with the remainder occurring over the next 3 secs.) 


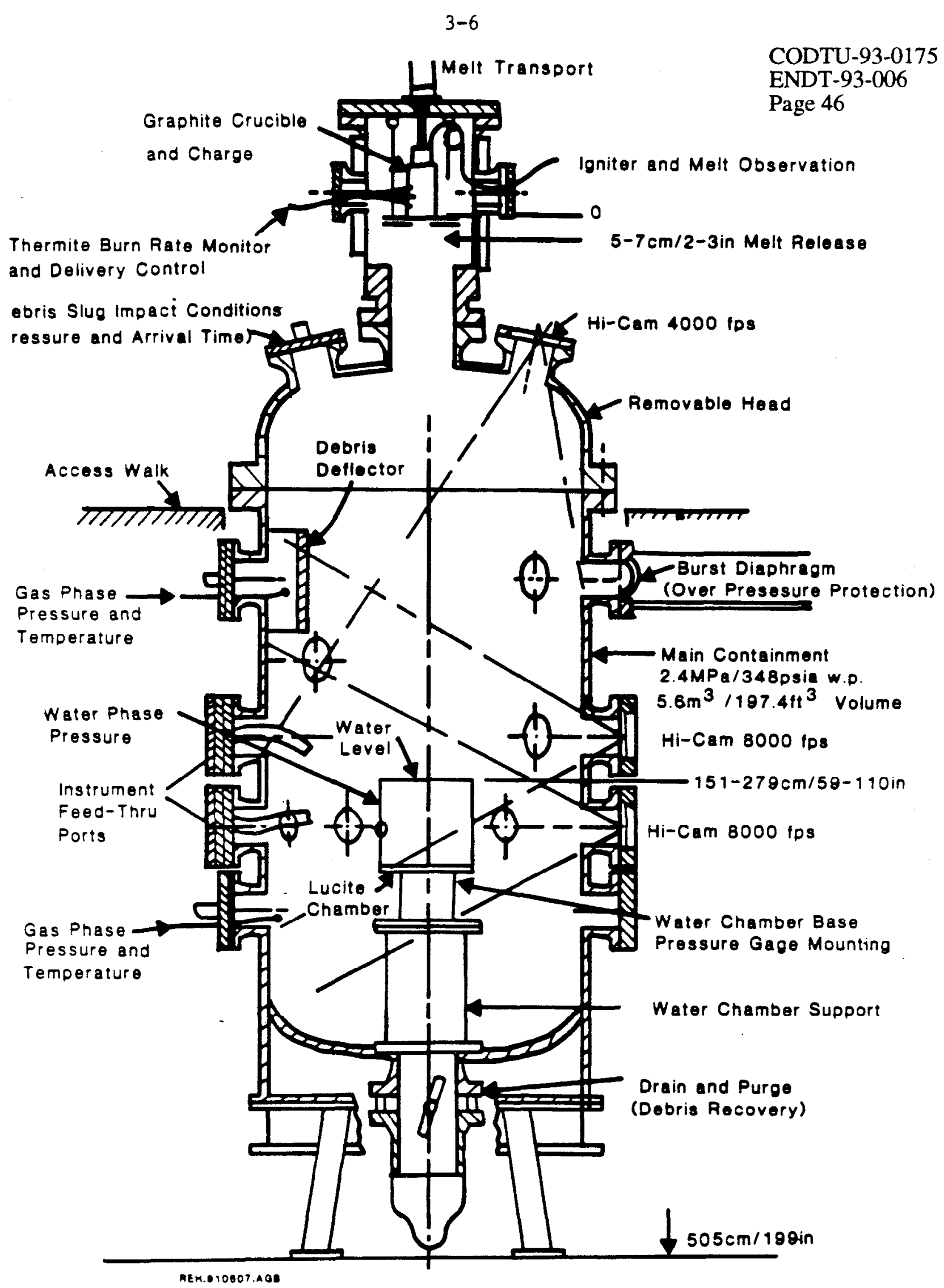

Figure 3-2 FITS containment chamber. 
Table 3-2

FITSB INITIAI, CONDITIONS AND OBSERVATIONS

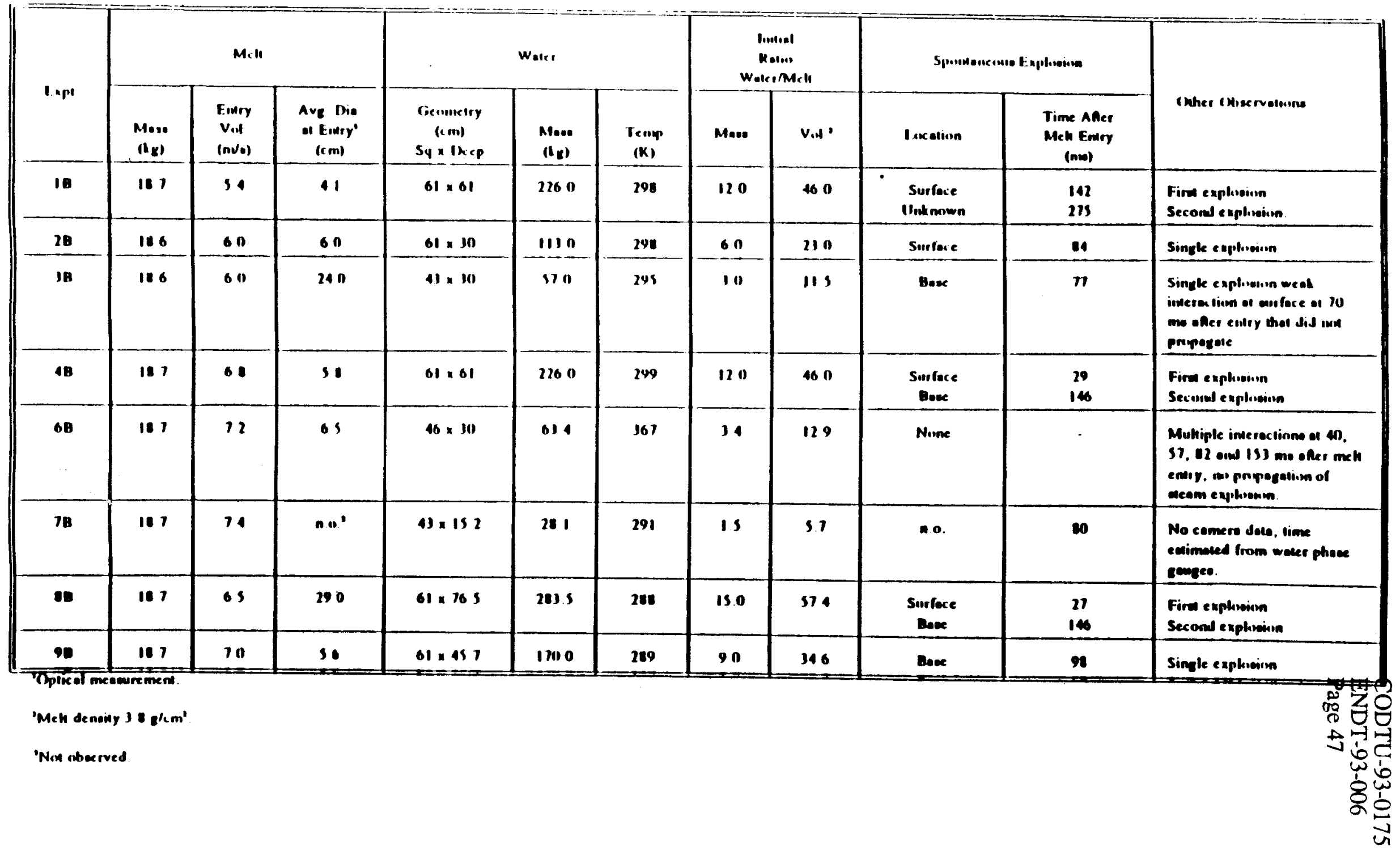


Table 3-2

(cont inued)

FITSB INITIAI, CONIITIONS ANI OBSERVATIONS

(Fng I sh Units)

\begin{tabular}{|c|c|c|c|c|c|c|c|c|c|c|}
\hline \multirow{2}{*}{ Inpe } & \multicolumn{3}{|c|}{ Mill } & \multicolumn{3}{|c|}{ Woles } & \multicolumn{2}{|c|}{ 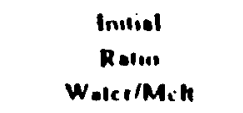 } & \multicolumn{2}{|c|}{ 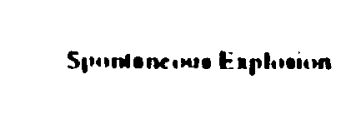 } \\
\hline & $\begin{array}{l}\text { Alene } \\
\text { (then) }\end{array}$ & $\begin{array}{l}\text { Finily } \\
\text { Vid } \\
\text { (n/a) }\end{array}$ & $\begin{array}{l}\text { Ave Dio } \\
\text { ot Einry' } \\
\text { (iiv) }\end{array}$ & $\begin{array}{l}\text { Fiecunacliy } \\
\text { (ini) } \\
\text { Sy }_{4} \times \text { Deep }\end{array}$ & $\begin{array}{l}\text { Alson } \\
\text { (Minen) }\end{array}$ & $\begin{array}{l}\text { Tenp } \\
(\bullet P)\end{array}$ & M... & vill: & Ismenion & $\begin{array}{l}\text { Tinve AA } \\
\text { MelW Eou } \\
\text { (ivi) }\end{array}$ \\
\hline 18 & 412 & 1771 & 161 & $24 \times 24$ & 41) 0 & $n$ & 120 & 460 & $\begin{array}{l}\text { Surfocic } \\
\text { IItuhmowne }\end{array}$ & $\begin{array}{l}142 \\
211\end{array}$ \\
\hline 2H & 1111 & 14 al & $1 \mathrm{kn}$ & $2+110$ & 2940 & 11 & 611 & 211 & Sunfface & 14 \\
\hline 14 & 110 & $19 \mathrm{hs}$ & 14 & 17.118 & 1241 & 716 & $3 n$ & 115 & Bax & $n$ \\
\hline$+B$ & 112 & 2111 & 214 & $24 \times 24$ & A1) II & $m u$ & 1211 & th 0 & $\begin{array}{c}\text { Sinforic } \\
\text { Bene }\end{array}$ & $\begin{array}{c}19 \\
146\end{array}$ \\
\hline 68 & 412 & 2162 & 236 & $10 \times 110$ & $114:$ & 21112 & 34 & 129 & Nenuc & \\
\hline 78 & 112 & 2421 & n o' & $17 \times 6$ & 61 95 & B4 4 & 15 & 57 & n 1. & 60 \\
\hline IB & $\$ 1$ & 213 & $\mid 1+1$ & $24 \times 30$ & 6250 & 590 & 150 & 574 & $\begin{array}{l}\text { Surfocie } \\
\text { Dance }\end{array}$ & $\begin{array}{l}27 \\
146\end{array}$ \\
\hline 98. & 112 & 2247 & 22 & 24,18 & 17479 & me & 90 & $1+0$ & Base & VI \\
\hline
\end{tabular}

'Meh Jenoity 1 \& $1 \mathrm{~cm}$

'Nix ninerved 
CODTU-93-0175

ENDT-93-006

Page 49

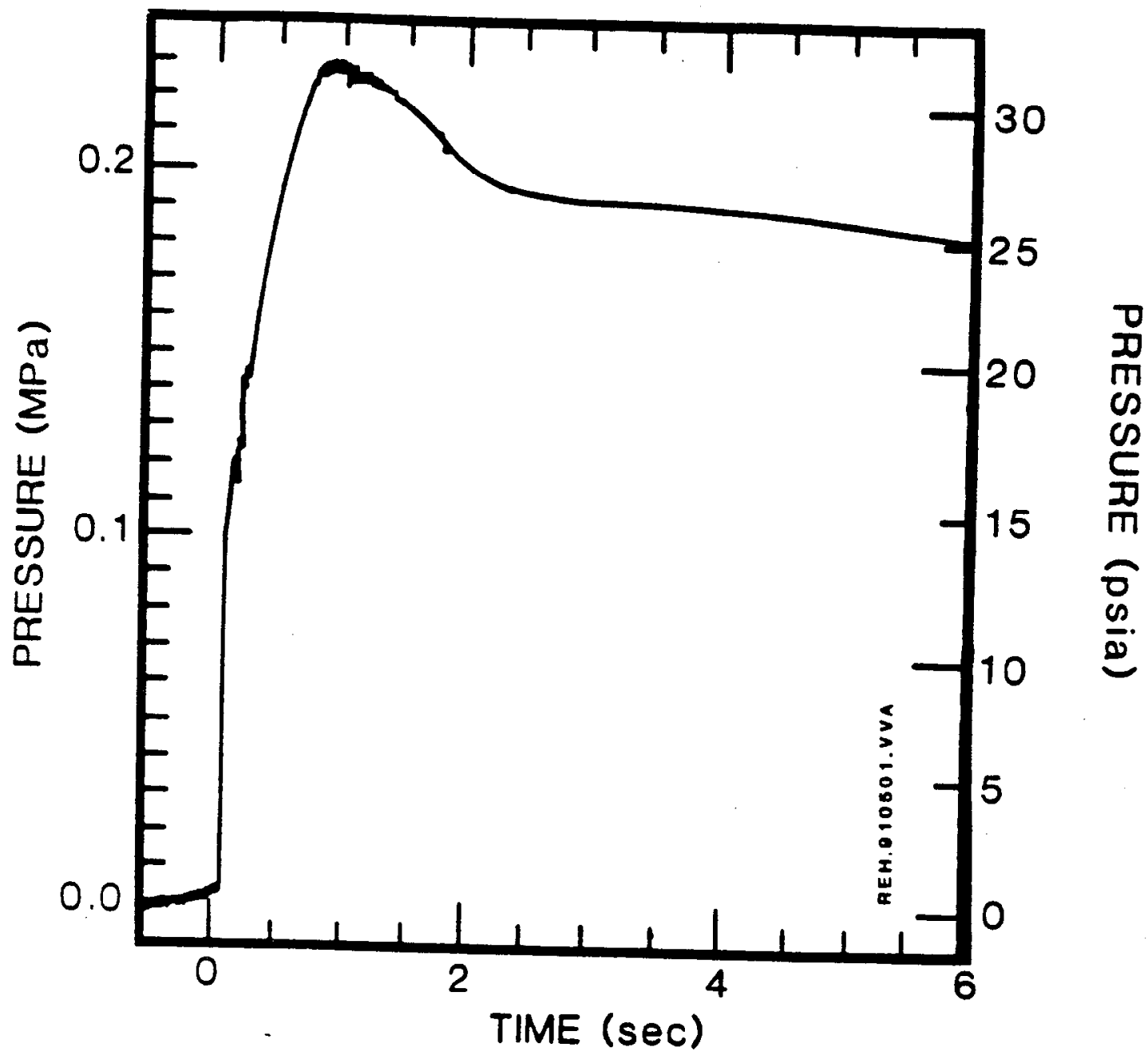

Figure 3-3 FITS2B chamber air pressure. 
CODTU-93-0175

ENDT-93-006

Page 50

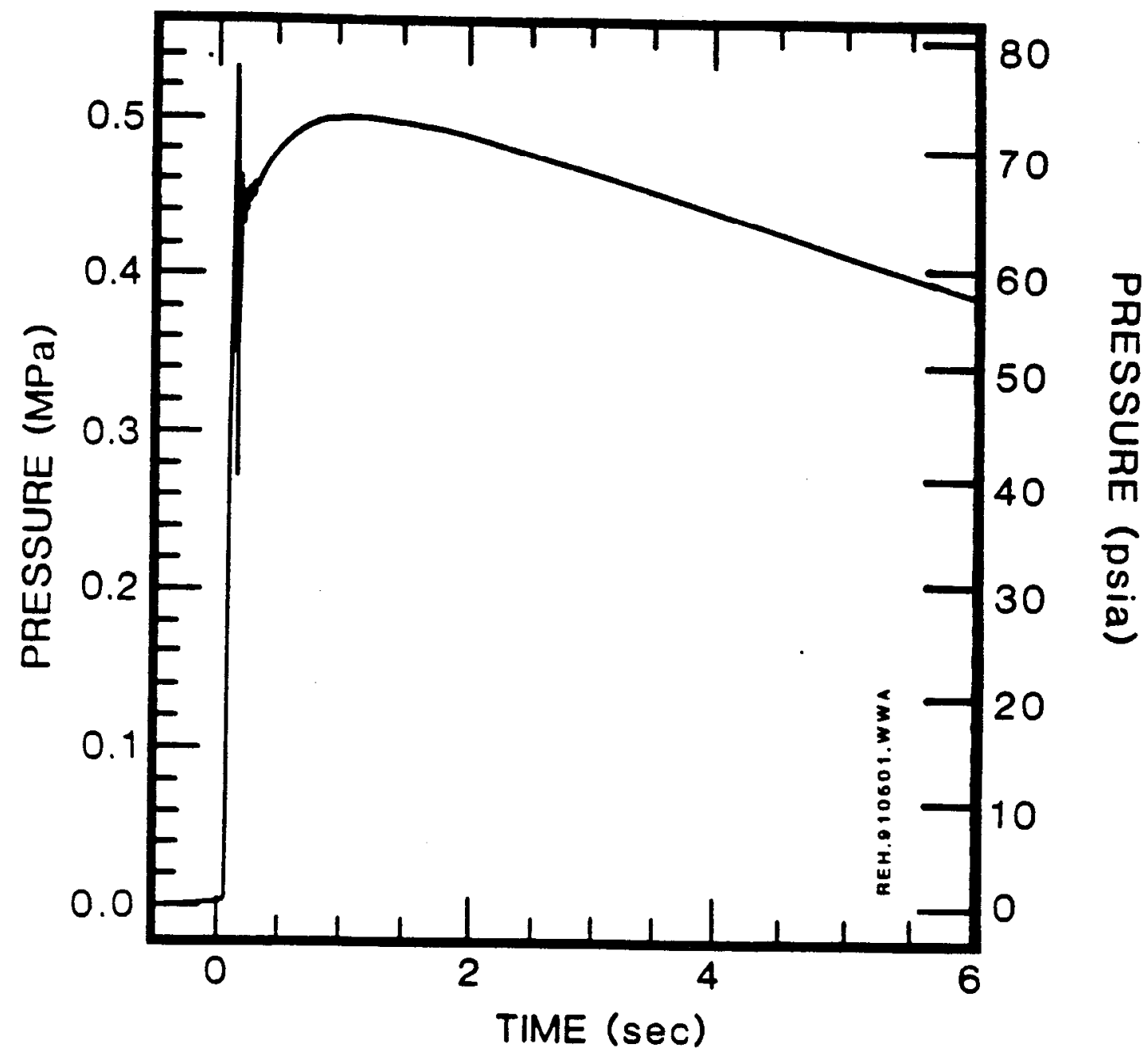

Figure 3-4 FIIS3B chamber air pressure. 


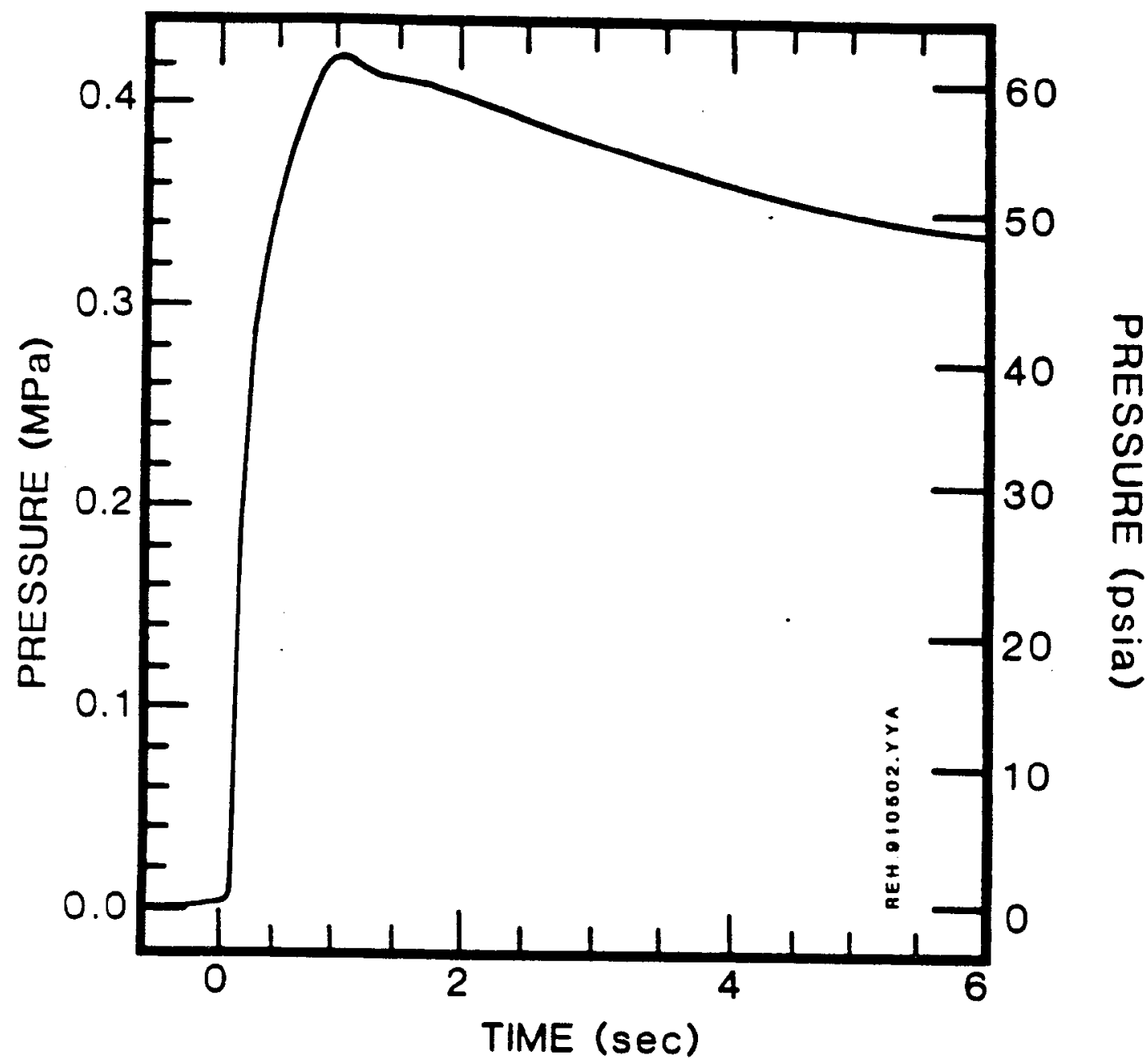

Figure 3-5 FITS6B chamber air pressure (saturated water). 
CODTU-93-0175

ENDT-93-006

Page 52

The average steam generation rate can be estimated by using the ideal gas equation.

$$
\frac{d P}{d t}-\frac{R T}{V} \frac{d N}{d t}
$$

where each varlable has the standard neaning. As an average representation, assume that the gas space pressure Increases $0.35 \mathrm{MPa}$ (51 psi) in $0.5 \mathrm{sec}$. The volume of the FITS vessel is $198 \mathrm{ft}^{3}\left(5.6 \mathrm{~m}^{3}\right.$ ) (Marshall, 1986) and, if an average gas temperature of $260^{\circ} \mathrm{F}$ (400K) is assumed, the steam generation rate is $2.65 \mathrm{lbn}-\mathrm{moles} / \mathrm{sec}(1.2 \mathrm{~kg}-\mathrm{moles} / \mathrm{sec})$, which is a mass addition rate of $47.5 \mathrm{lbm} / \mathrm{sec}(21.6 \mathrm{~kg} / \mathrm{sec})$. As the melt enters the vessel, the dynamic interactions (either explosive or non-explosive) would expel melt and water from the lucite test vessel. To provide an equivalent basis for comparison with the FAI/EPRI Mark I tests, the steaming rate should be represented as a heat flux using the cross-sectional area of the FITS vessel ( $\left.-19.4 \mathrm{ft}^{2}\left(1.8 \mathrm{~m}^{2}\right)\right)$. Using this area, the average heat flux from the melt to the water is about $8.6 \times 10^{\circ} \mathrm{Btu} / \mathrm{h}-\mathrm{ft} \mathrm{t}^{2}\left(27 \mathrm{MW} / \mathrm{m}^{2}\right)$, 1.e. a value in close agreement with that observed in the Mark I experiments.

\section{1 .3 Swmary}

In summary, the results from new, significant scale experiments with greatly different geometries have been complled to develop a basis on which to provide interpretation for the furnace response due to rapid steam generation by dynamic interactions. Specifically, dynamic interactions should be considered with steam generation rates from $3.2 \times 10^{\circ}$ to $9.5 \times$ $10^{\mathrm{B}} \mathrm{Btu} / \mathrm{h} \cdot \mathrm{ft}^{3}$ (10 to $30 \mathrm{mw} / \mathrm{m}^{2}$ ). The projected area of the compartment floor should be used as the pertinent value for determining the total energy production rate. This can then be used to determine if the uncertainties in this range provide for any substantial change in the overall accident evaluation. 


\subsubsection{Possible Mechanion for Maxim Stem Generation Rate}

The information presented above was taken from a wide variety of experimental Information and provides a substantial data base for describing the maximum melt-water stean generation rate. One can provide a theoretical basis for heat fluxes in the range of $10.4 \times 10^{6} \mathrm{Btu} / \mathrm{h}$ - $\mathrm{ft}^{2}$ ( 30 $\mathrm{MW} / \mathrm{m}^{2}$ ) for a system with co-dispersed debris and water as deplcted in Figure 3-6. A steam velocity sufficient to levitate and separate the water droplets from the high temperature dense debris is given by

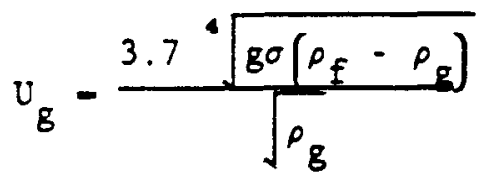

where $g$ is the acceleration of gravity, $\sigma$ is the steam-water surface tension and $\rho_{f}$ and $\rho_{g}$ represent the saturated water and steam densities respectively. If this is considered to be the maximum steam production rate which could exist without separation of the water droplets from the co-disperse configuration, then the heat flux associated with the vapor production rate is given by

$$
q / A-3.7 h_{f g} \sqrt{\rho_{g}} \sqrt[4]{g \sigma\left(\rho_{f}-\rho_{g}\right)}
$$

where $h_{f g}$ is the latent heat of vaporization. Substituting the appropriate values for steam and water at 1 atm into this expression results in a value of $10.4 \times 10^{\circ} \mathrm{Btu} / \mathrm{h}-\mathrm{ft}^{2}\left(30 \mathrm{~mW} / \mathrm{m}^{2}\right)$; a value in agreement with those observed in the various experiments. Hence, the major ramification of an explosive interaction could be the co-dispersion of melt and water which then continues to transfer energy and vaporize water into, the atmosphere at a rate limited by the ability of the water droplets to remain as part of the co-dispersed medium. 


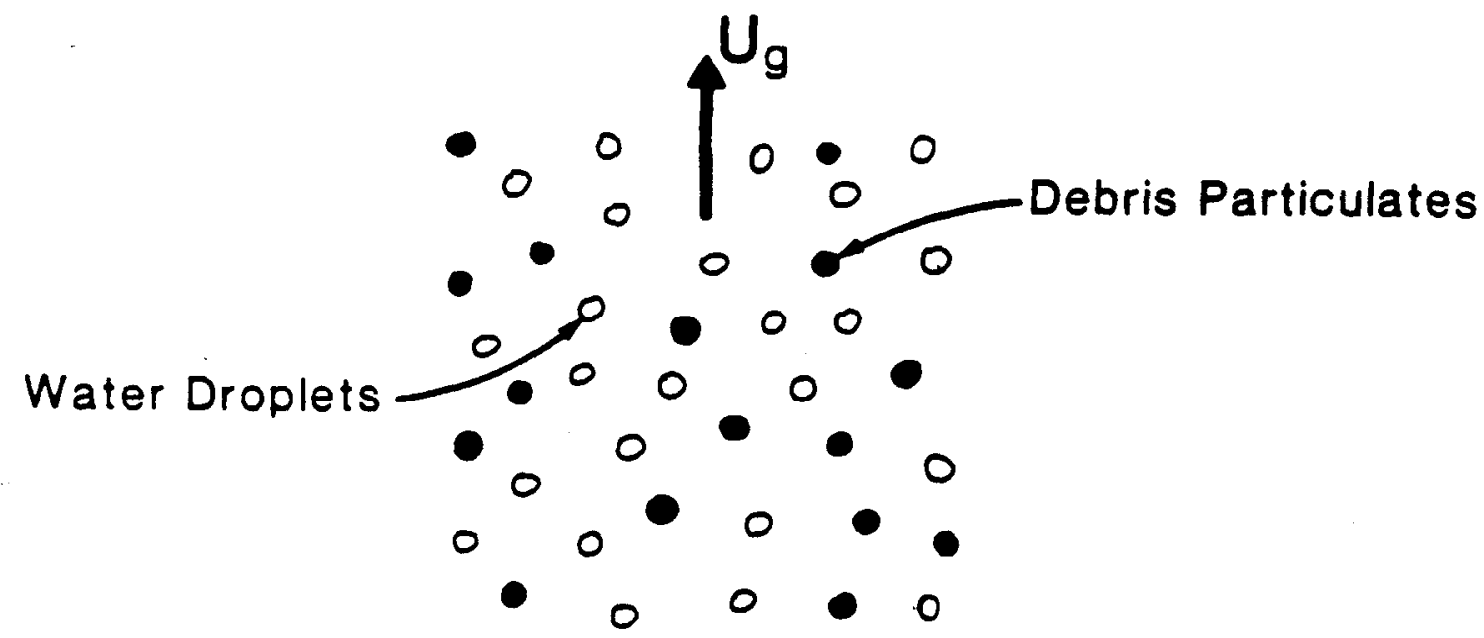

\section{(a) Co-Dispersed Configuration}

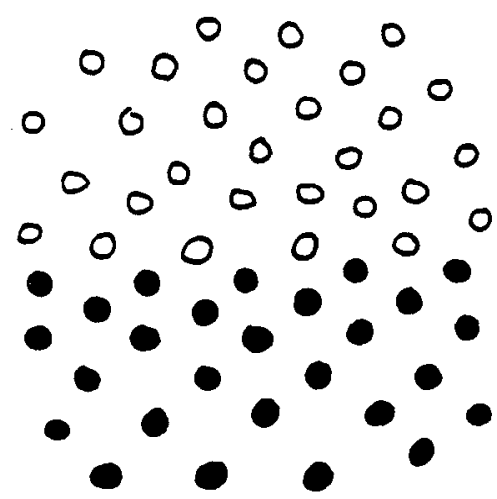

(b) Configuration if the Droplets are Fluidized

Figure 3-6 Debris dispersion configuration. 
CODTU-93-0175

ENDT-93-006

Page 55

\subsubsection{Shock Daves fron Stean Boplogions}

Modeling of the shock waves Induced by steam explosions is only necessary if $1 t$ is concelved that these would challenge the furnace integrity. Figure 3-7 taken from (Glass, 1974) 1llustrates the decay of substantial shock waves in alr as the shock wave expands. A slope corresponding to a pressure amplitude decay proportional to $1 / r^{2}$ is also included for reference and provides a reasonable assessment of the decay characteristic for strong waves. If anything, the higher amplitude portion of the curve decays faster than this simplified representation. If an interaction zone size is postulated along with a maximum pressure for the interaction, this type of decay can be applied to the Sandia FITS experiments to compare the measured shock wave pressures in these tests with this decay characteristic. Table 3.2 summarizes the experimental conditions for the FITSB series, Including the size of the test chamber in which the thermite and water were mixed. As an interaction zone, half of the square dimension is used as the radius for the initial calculation. Also, for the peak pressure achieved in the interaction zone one half the critical pressure ($1450 \mathrm{psi}$ or $10 \mathrm{MPa}$ ) is used since this corresponds to a condition in which the critical size bubble embryos equal the size for thermally dominated bubble growth (Henry, et al., 1979). For pressures greater than this value, the vapor cannot be produced at a pressure higher than the surrounding ambient. Other experiments have shown this value to be an upper bound of the pressure that can be achieved when the system is not tightly constrained.

The expansion from the interaction zone out to the diameter of the FIIS vessel, $2.5 \mathrm{ft}(0.76 \mathrm{~m})$ radius, is performed following the approximation shown in Figure 3-7. Since only three different size vessels were used in the eight experiments, only three different shock wave pressures incident on the FITS vessel wall are calculated by this approximate method. These are illustrated in Table 3-3 for the different experiments. As illustrated, this technique substantially overestimates the measured pressure at the FITS vessel boundary. This is not surprising since the curve shown in Figure $3-7$ is compared to chemical explosion which is typically 


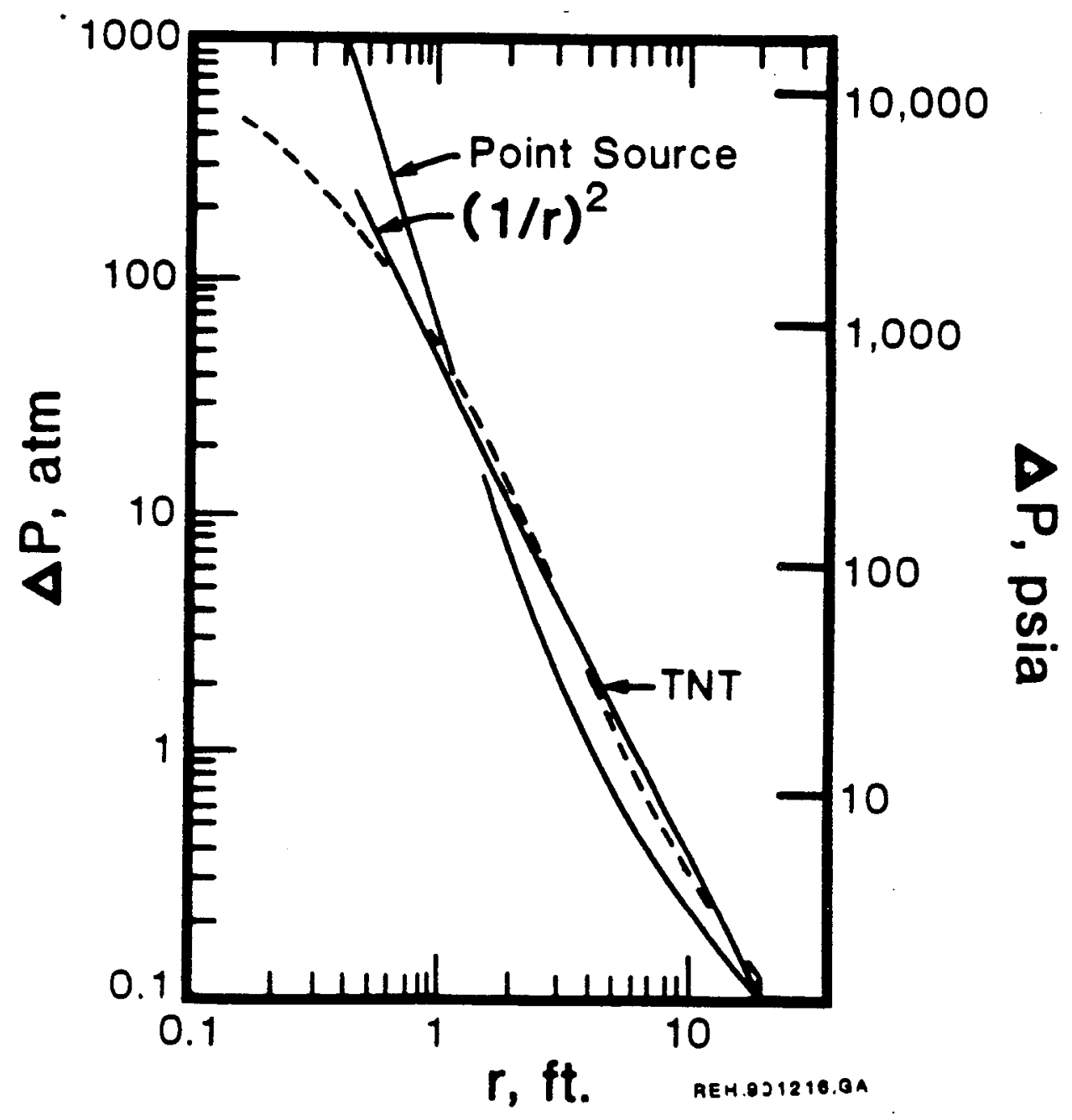

Figure 3-7 Comparison of shock wave pressures for TNT and point source explosions. 
Table 3-3

CHAMBER AIR PRESSURE DATA FROM FITSB

(Times From Melt Entry)

\begin{tabular}{|c|c|c|c|c|c|}
\hline \multirow{3}{*}{ Expr. } & \multicolumn{4}{|c|}{ Steam Explosion Phase } & \multirow{3}{*}{$\begin{array}{l}\text { Calculaced } \\
\text { Preasure } \\
\text { Peak } \\
\text { (MPA/psig) }\end{array}$} \\
\hline & \multicolumn{2}{|c|}{$\begin{array}{c}\text { Explosioo } \\
\text { (s) }\end{array}$} & \multicolumn{2}{|c|}{$\begin{array}{l}\text { Proware Peates } \\
\text { (MPI/paig) }\end{array}$} & \\
\hline & $1 s t^{t}$ & 2ad & lst & $20 d$ & \\
\hline $1 B$ & 0.144 & 0.282 & $0.095 / 12.78$ & $0.197 / 28.6$ & $1.6 / 218$ \\
\hline 4B & 0.029 & 0.146 & $0.020 / 2.9$ & $0.500 / 72.5$ & $1.6 / 218$ \\
\hline $8 B$ & 0.017 & 0.144 & $0.01 / 1.45$ & $0.373 / 54.1$ & $1.6 / 218$ \\
\hline $2 \mathrm{~B}$ & 0.087 & a.o.: & $0.220 / 31.9$ & o.o. & $1.6 / 218$ \\
\hline $3 B$ & 0.081 & a.o. & $0.440 / 63.8$ & a.o. & $0.7 / 87$ \\
\hline $6 B$ & D.o. & D.o. & D.o. & n.o. & $0.9 / 116$ \\
\hline $7 \mathrm{~B}$ & $=0.20$ & D.o. & $0.01 / 1.45$ & a.o. & $0.7 / 87$ \\
\hline $9 \mathrm{~B}$ & 0.102 & a.o. & $0.210 / 30.45$ & o.o. & $1.6 / 218$ \\
\hline
\end{tabular}

I Time taken from star to pressure rise. Zero time taken from avernge of two active melt position sensors 2.5 im above waler surface.

: Not observed. 
more energetic and has a stronger shock wave than those generated by steam explosions.

\subsubsection{Yetal-Dater Reactions During Bolosive Interections}

One experiment has been performed in which the high temperature melt dropped into water contained highly reactive metals and measurements were made with respect to the extent of hydrogen formation (Wang, et al., 1989). In these experiments, a thermite flxture representing the fuel naterial from a light water reactor was dropped into water. As part of the nixture, highly reactive chromium was included and measurements of the subsequent hydrogen formed during the quenching process were made. The experiments typically showed that when the melt was dropped into water, a few percent, perhaps as much as 58 , of the metal was oxidized. This gives a demonstration of the competitive processes between quenching of the high temperature melt and the exothermic oxidation process ongoing at the same time.

\subsection{Eydrogen Burns}

Numerous experiments have been performed to establish the combustion limits of hydrogen as a function of hydrogen concentration. The generally accepted lower flammability limit for upward flame propagation in air is 48 by volume hydrogen. Horizontal flame propagation can take place with about 68 by volume hydrogen and downward propagation takes place at about 88 by volume hydrogen. The dominant governing process that controls burn completeness in a quiescent environment near the flamability limits is buoyancy-driven flame propagation. If a mixture containing 48 by volume hydrogen is ignited, the flame propagates upward due to buoyancy and an incomplete burn will result unless there is another mechanism for flame propagation. If a mixture is capable of local ignition, preignition turbulence results in more extensive flame propagation and larger burn completeness. Combustion limits have also been shown by experinent to be a function of Inert gas concentration. One such study (Benedick, et al., 1984) provided a demonstration of the inerting capabilities of carbon dioxide, the results for these experiments performed in the vGES test vessel at Sandia are 1llustrated in Figure 3-8, which is taken from 
(Benedick, et al., 1984). This also shows the results of other experiments at Lawrence Livermore and Sandia using steam as the inerting material. As shown, the atmosphere becomes inerted at a $\mathrm{CO}_{2}$ concentration of 528 .

An experimental program was initiated, carried out and analyzed by Westinghouse (Tsal, et al., 1982) to determine the influence of steam in the atmosphere as an inerting medium. The results clearly demonstrated that steam had a strong effect on both the ability to ignite the nixture and the combustion completeness. A correlation was developed for the critical flame temperature to describe the influence of steam. (Critical flame temperature is a means of representing whether the mixture is combustible.)

Another substantial experimental program was performed in the FITS vessel at Sandia to clearly define the combustion boundaries for a hydrogen-alr-steam mixture both in quiescent conditions and in a turbulent environment (fans operational). This set of experiments is particularly meaningful to accident management evaluations because ( 1 ) steam is the inerting medium, (2) the boundary is clearly defined and (3) the experimental apparatus took great pains to attempt ignition of the mixture. Figure 3-9 taken from (Marshall, 1986) illustrates the test results for the "fans off" state and Figure 3-10, also taken from (Marshal1, 1986), depicts the test data for the "fans operational" condition. Those conditions which are represented as "no burn" represent the mixture state in which neither repeated spark initiators nor a glow plug were capable of initiating a burn. Based on these experimental results, it can be concluded that even in the presence of turbulence induced by the accident condition, one still observes steam inerting and well defined flamability limits.

The experimental information was subsequently formulated into a correlation to represent the combustion infts. This is given by

$$
\text { Steam }=100-\mathrm{H}_{2}-37.3 \mathrm{e}^{-0.007 \mathrm{H}_{2}}-518.0 \mathrm{e}^{-0.4888 \mathrm{H}_{2}}
$$

and is compared to the experimental results in Figure 3-11. Hence, if sufficient steam is released to a non-inerted volume to produce a steam 


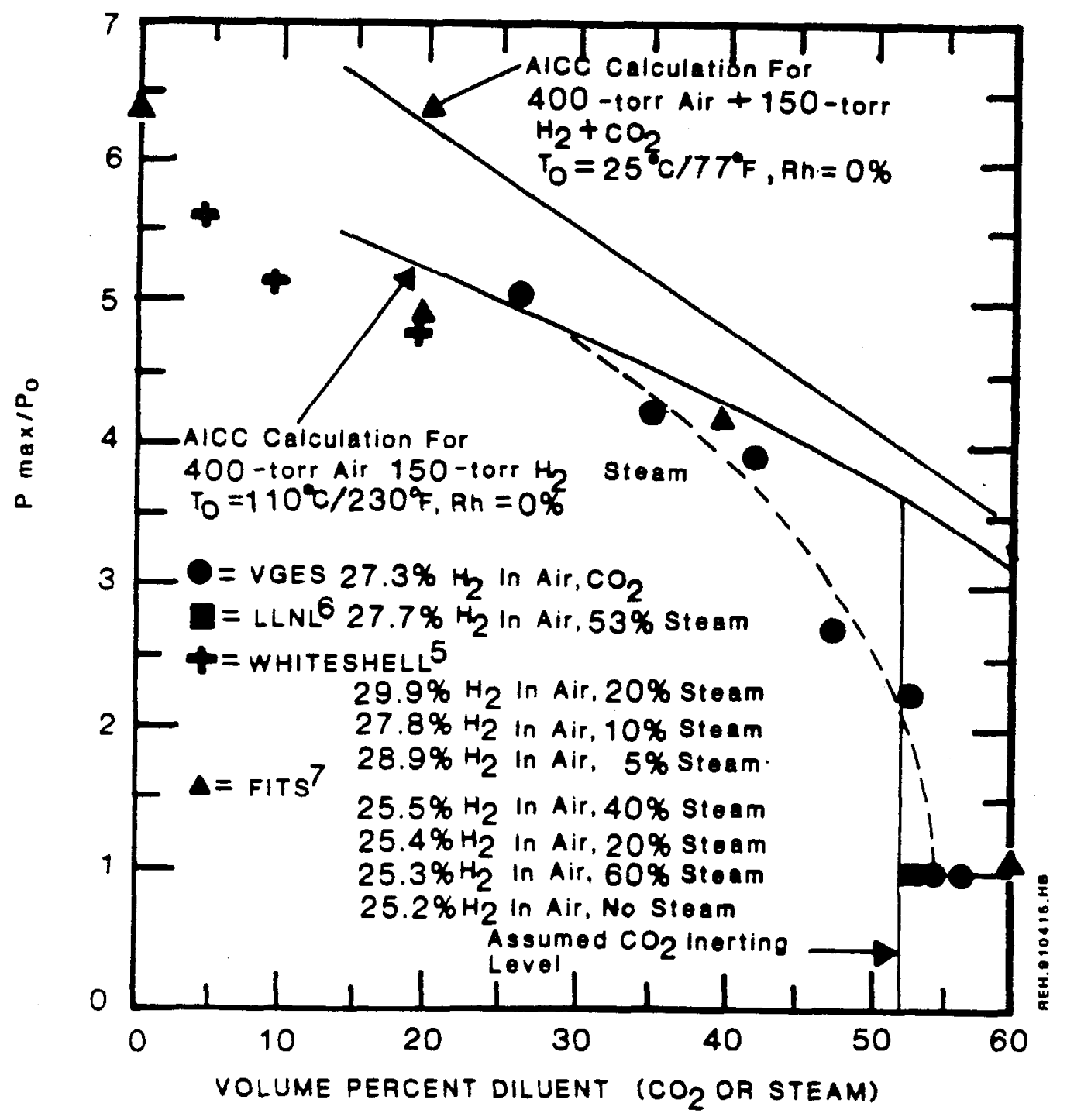

Figure 3-8 Normalized peak pressure $(P / P$ ) for hydrogen: air:diluent mixtures, comparing $\mathrm{CO}_{2}$ and steam (AICC - adiabatic isochoric complete combustion, $\mathrm{Rh}=$ relative humidity) (Benedick, 1984). 


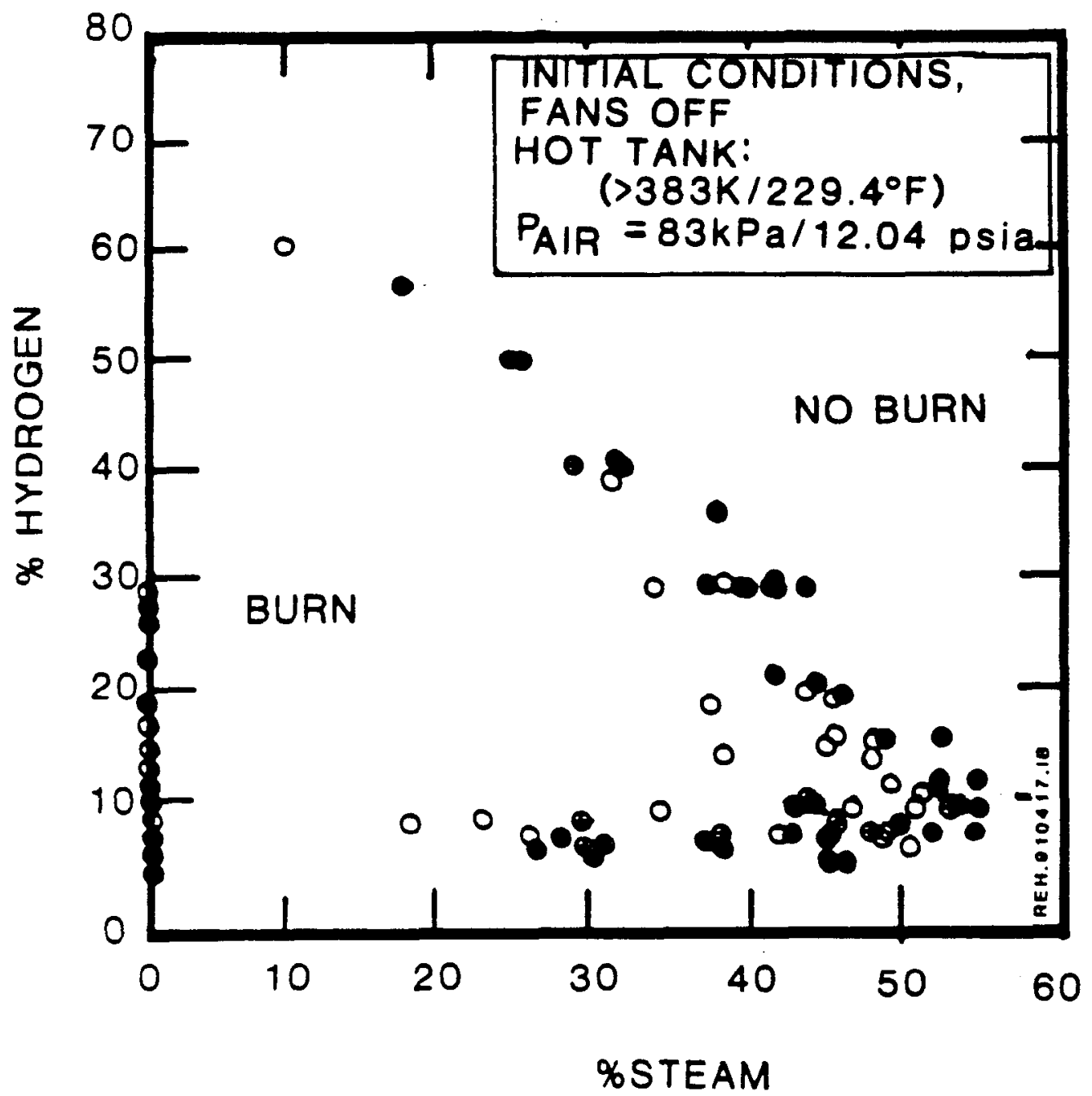
LEGEND,
OBURN
- MARGINAL BURN ONO BURN

Figure 3-9 Hydrogen:air:steam flammability data with fans off (Marshall, 1986). 

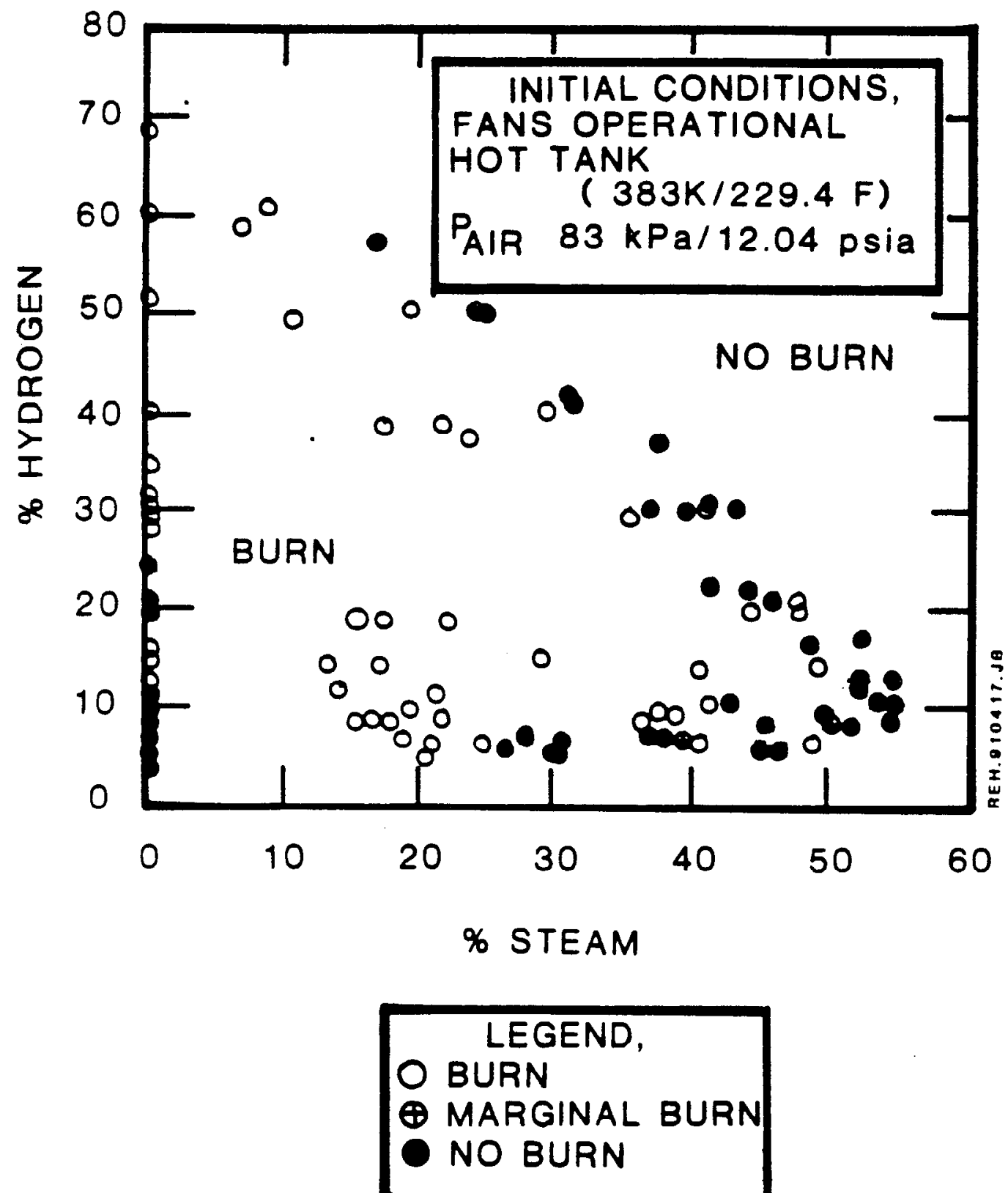

Figure 3-10 Hydrogen:air:steam flammability data with fans operational (Marshall, 1986). 
CODTU-93-0175

ENDT-93-006

Page 63

partial pressure of slightly over one atwosphere, hydrogen combustion would be precluded regardless of the hydrogen mass accumulated in the volume. 
CODTU-93-0175

ENDT-93-006

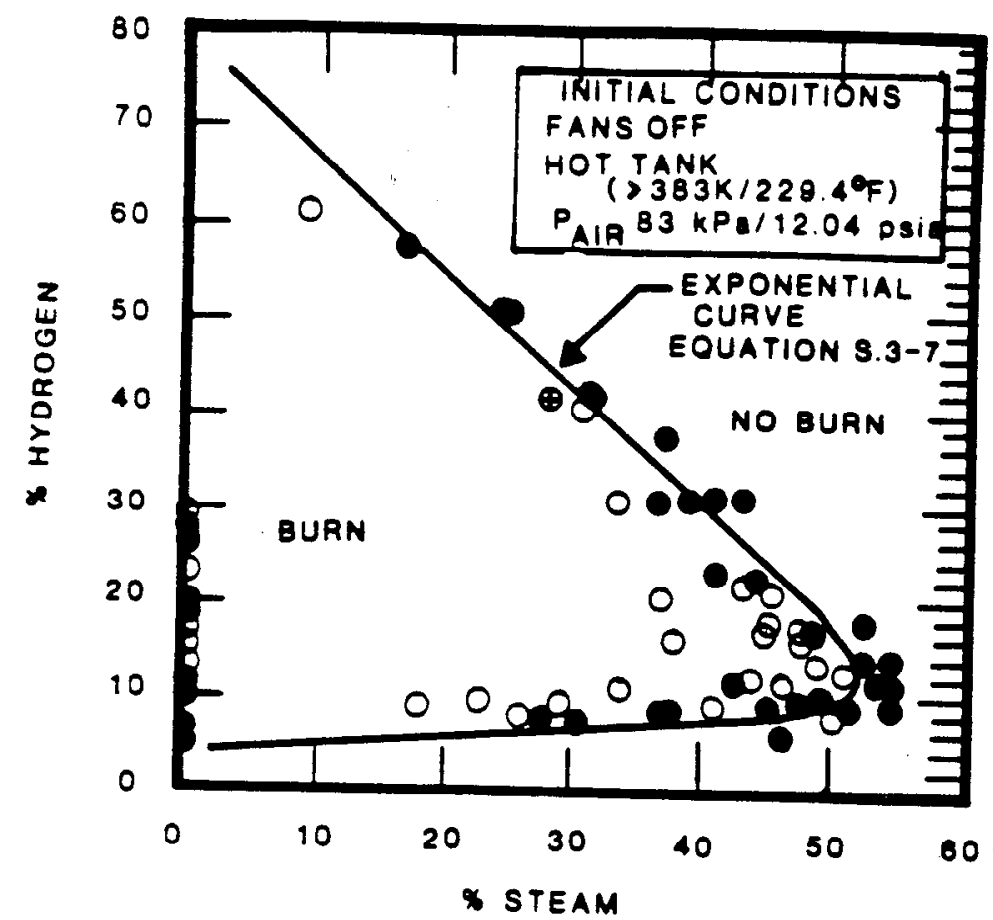

Page 64

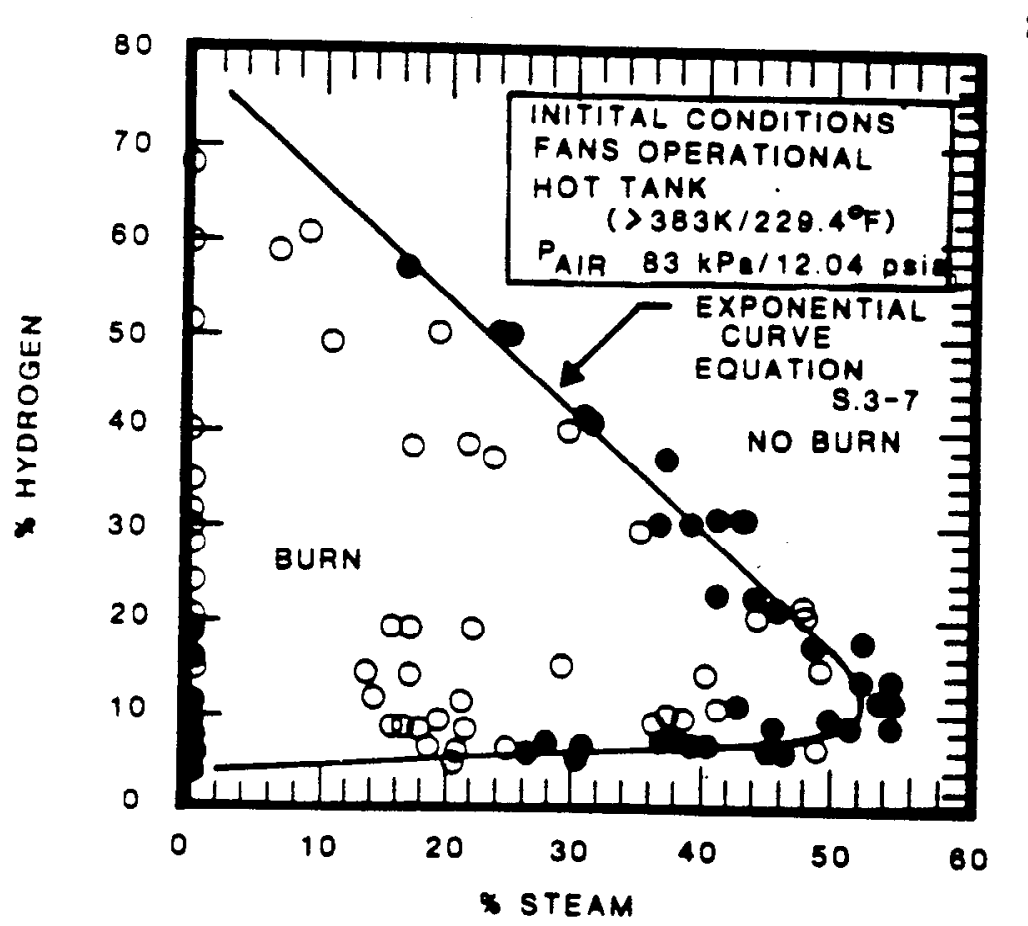

\begin{tabular}{|l|} 
LEGEND \\
BUAN \\
MARGINAL BURN \\
NO BURN
\end{tabular}

Figure 3-11 Hydrogen:air:steam flamability data with fans on and of shown with the exponential curve fit (Marshall, 1986). 


\subsection{STEAY EXPLOSION GTAUDATION}

As discussed in (FAI, 1990a), subcooled coolant conditions are generally required to produce intermixing and explosive interactions for high temperature systems, assuming a sufficient trigger is avallable. Only in case of multiple fallures (as discussed in section 2.0) where subcooled water may be present as a result of prior pressurization due both to loss of pressure boundary integrity and internal coolant circuit integrity does a potential for intermixing and an explosion occurrence exist. Even in this unlikely event an energetic explosive event can be ruled out as dis. cussed below.

Based upon discussions in Sections 2 and 3 , the most likely potential for interaction between the molten uranium metal and the coolant water would appear to be following accumulation of the material within the mold and on the bottom of the vacuum chamber. Given isolation of the cooling coil water as discussed in Section 2, the accumulated water level within the mold would be limited to about $0.06 \mathrm{~m}$ and on the floor of the vacuum furnace would be 1 imited to about $0.045 \mathrm{~m}$. It is noted that elevated temperature of the mold would prevent accumulation of subcooled water as vigorous boiling would be experienced as the water tries to enter the mold. The boiling water would prevent any subsequent energetic thermal interaction with the molten metal. Assuming heatup of the mold prior to establishing molten metal condition should therefore be considered as part of the operating procedures.

Furthermore, the shallow layers of water would not allow the necessary pre-mixing configuration to be established between the molten metal and the water, a prerequisite of energetic interactions. This can be illustrated by considering the required water pool height required to completely break up a molten metal jet given by (Epstein and Fauske, 1989)

$$
L / D-6.25\left(\rho_{M} / P_{w}\right)^{1 / 2}
$$

where $L(w)$ - height of water pool or layer, 
D (II) - diameter of the molten jet pour,

$\rho_{M}\left(\mathrm{~kg} \mathrm{~m}^{-3}\right)$ - density of uranium metal, and

$\rho_{w}\left(k_{B} m^{-3}\right)$ - density of water.

Considering the molten uranium fet pour diameter to be of the same dimension as the crucible stopper rod $(-0.02 \mathrm{~m})$, we estimate a required breakup length of about $0.5 \mathrm{~m}$, 1.e., about an order of magnitude larger than the avallable water pools $(-0.05 \mathrm{~m})$. We conclude from the above considerations that the required premixing configuration of molten particles interdispersed in equal volume of the volatile fluid necessary for an energetic interaction, cannot develop. Instead a configuration consisting infially of a molten uranium metal layer and a water layer separated by a steam blanket would likely develop. (We note that instantaneous physical contact between the molten metal and water as the material descend into the mold or onto the bottom of the vacuum chamber, would at the very worst result in violent splashing and no significant pressure generation.) The development of a largely stratified flow regime is known to produce relatively benign thermal interactions involving only a very small fraction of the molten material (Bang and Corradini, 1991).

Given the presence of a timely trigger that would collapse the vapor layer locally while the uranium metal is still molten (note that the metal would cool rapidly due to the presence of the cold and massive vacuum chamber floor - 1 in. steel plate as well as heat removal due to film bolling), the potential for a propagating steam explosion in connection with the initially separated or stratified regime needs to be considered.

For systems which have demonstrated propagating vapor explosions, the corresponding propagation velocity has been observed to be of the order of $100 \mathrm{~m} / \mathrm{s}$ (Board and Hall, 1976). Since the fragmentation and intermixing velocity cannot exceed the measured propagation velocity, a first order estimate of the time required for fine scale fragmentation of the molten metal and water layers can be obtained fron (Bankoff, 1978): 
CODTU-93-0175

ENDT-93-006

Page 67

$$
--3 \frac{d}{U} \sqrt{\frac{\rho_{M}}{\rho_{w}}}
$$

where $d$ is set equal to the thickness of the accumulated molten uranium layer $(-0.007 \mathrm{~m}) ; U$ is the propagation velocity; and $\rho$ and $\rho_{c}$ are the uranium metal and water densities, respectively, and results in a fragmentation time of about $10^{-3} \mathrm{~s}$, which is characteristic of thermal explosion time scale.

However, for systems which have denonstrated propagating vapor explosions, $T_{i}$ is generally well above the critical temperature, while the observed peak shock pressure at the source is well below the critical pressure (Henry, et aI., 1976; Henry and Fauske, 1979). The dynamic impact pressure within the liquid ( $\rho$ ua, where $\rho$ is the liquid density, $u$ is the propagation velocity and $a$ is the velocity of sound in the liquid) resulting from vapor collapse would therefore appear to be the main pressure source for suppressing the retarding effect due to vaporization during the necessary fine scale fragmentation and intermixing process. In view of the limited water layer, the time scale for intermixing becomes extremely small and to a first order is given by $d / a$. Required time to avoid evaporative forces is therefore of the order of $(0.05 / 1500)-10^{-5} \mathrm{~s}$ which is much smaller than the estimated breakup time, Equation (4-2). It follows that no significant fine scale intermixing can take place, leading to the absence of any damaging steam explosion pressures. As discussed in section 3, steaming rates resulting from such benign interactions can be enveloped by considering an equivalent surface heat flux of about $30 \mathrm{MW} / \mathrm{m}^{2}$. 


\subsection{HYDROGES BURP GPAITATTON}

Given multiple fallures (crucible cracking, coolant coll fallure and vacuum chamber pressure fallure resulting in inflow of air) as discussed in Section 2.0 , the possiblity of $\mathrm{H}_{2}$-deflagration also needs to be evaluated.

Consideration of chemical reaction between molten uranium and water and formation of $\mathrm{H}_{2}$ according to

$$
\mathrm{U}+2 \mathrm{H}_{2} \mathrm{O} \rightarrow \mathrm{UO}_{2}+2 \mathrm{H}_{2}
$$

indicates that oxidation of only about 0.338 of the available uranium ( $100 \mathrm{~kg}$ ) would satisfy the lower flammability limit ( 58$)$ for $\mathrm{H}_{2}$ in dry air.* This assumes that $\mathrm{H}_{2}$ is accumulating in the vacuum chamber ( -1275 2) as it is being formed, e.g., $\mathrm{H}_{2}$ is not escaping through the leak(s) or vents as it is being formed. However, as discussed in Section 3, the presence of inert steam material in the vacuum chamber will have a sig. nificant effect on the potential as well as the severity of a $\mathrm{H}_{2}$ deflagration. The presence of steam in excess of 50 volume percent in the vacuum chamber eliminates the deflagration potential altogether independent of $\mathrm{H}_{2}$ concentration.

The rate equation for metal oxidation in the temperature range of interest is given by (Baker, 1983)

\footnotetext{
*The required quantity of stean to oxidize $0.33 \mathrm{~kg}$ of uranium is about 0.05 $\mathrm{kg}$. While this quantity is much smaller than the quantity of water assumed avallable ( 10 gallons) in the multiple fallure scenario, it is well above the water vapor quantity that would result if the vacuum chamber were to be filled by amblent air as a result of a broken viewport (assuming 100 relatively humidity, the water vapor quantity would be limited to about $0.02 \mathrm{~kg}$ ). Furthermore, in the case of an intact vacuum chamber, a small but steady water leak could oxidize uranium but would not result in a damaging mixture due to lack of oxidizer (i.e., air).
} 
CODTU-93-0175

ENDT-93-006

Page 69

$$
w^{2}-7.5 \cdot 10^{5} t \exp (-25,000 / \mathrm{RT})
$$

where $w\left(\mathrm{mg} / \mathrm{cm}^{2}\right)$ - amount of metal oxidation per unit area for a specified time,

$t(s)$ - duration of metal oxidation,

$R$ (cal/g-mole-K) - ges constant (1.987), and

$T(K)$ - metal temperature ( - 1773K).

Considering the extreme case of setting the exposed metal surface area equal to the maximum possible metal pool surface area of $0.84 \mathrm{~m}^{2}$ or 8365 $\mathrm{cm}^{2}$ and the metal temperature equal to $1500^{\circ} \mathrm{C}$ or $1773 \mathrm{~K}$, Equation (5-1) suggests a time interval of $t \approx 2.6 \mathrm{~s}$ to oxidize enough metal $(w \approx 40$ $\mathrm{mg} / \mathrm{Cm}^{2}$ ) to satisfy the lower flamability limit ( -58$)$ for $\mathrm{H}_{2}$ assuming dry air.

A lower bound steaming rate can be evaluated assuming film bolling where the heat flux is given by

$$
q=\sigma\left(I_{M}-I_{s}^{4}\right)+h_{c}\left(T_{M}-T_{S}\right)
$$

where $q\left(w^{-2}\right)-f i l m$ boiling heat flux,

$$
\sigma\left(w \mathrm{~m}^{-2} \mathrm{~K}^{-4}\right) \text { - Stefan-Boltzman constant }\left(5.65 \cdot 10^{-8}\right) \text {, }
$$$$
T_{M}(K) \text { - uranium metal cemperature ( - 1773K), }
$$

$I_{s}(K)$ - steam saturation temperature (- 373K),

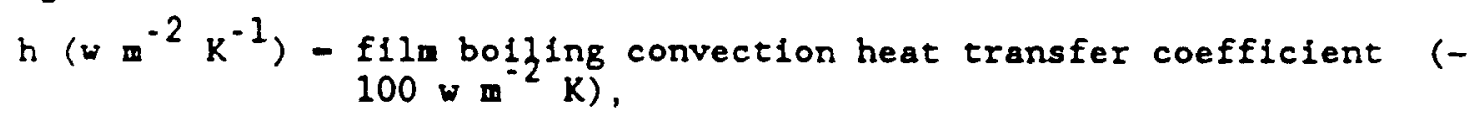

and results in a heat flux of about $-700,000 \mathrm{w} \mathrm{m}^{-2}$. The above heat flux gives rise to a steaning rate of about $0.26 \mathrm{~kg} \mathrm{~s}^{-1}$ based upon a pool surface area of about $0.84 \mathrm{~m}^{2}$.

Recalling the time interval to oxidize enough metal to reach the lower flamability limit of $\mathrm{H}_{2}$ in dry air of about $2.6 \mathrm{~s}$, results in about $0.7 \mathrm{~kg}$ 
CODTU-93-0175

ENDT-93-006

Page 70

of steam. This is equivalent to about $37.6 \mathrm{~g}$-moles or 842 \& which translates to about 66 volume percent of steam in the vacuum chamber. (Note that less than 108 of the steam production is enough to satisfy metal oxidation.)

It follows from the above considerations and the discussion provided in section 3, that sufficlent steam inerting will take place in the vacuum chamber for the postulated accident scenarios to eliminate the potential for $\mathrm{H}_{2}$ deflagration. 
CODTU-93-0175

ENDT-93-006

Page 71

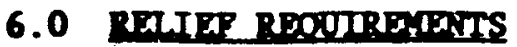

Given isolation of the cooling coll water in case of leakage as discussed in Section 3.0, the accumulated water level on the floor of the vacuum furnace is 1 inited to about $0.045 \mathrm{~m}$. Considering the shallow water pool, a very conservative estimate of the steaming rate resulting from interaction between nolten uranium dripping into the water located on the floor of the vacuun chamber is estiaated to be about $11 \mathrm{~kg} \mathrm{~s}^{-1}$. This value results from using the peak experinental heat flux value of $30 \mathrm{~m} \mathrm{~m}^{-2}$ and the maximum possible pool surface area of $0.84 \mathrm{~m}^{2}$, which is an area consistent with the manner in which the heat flux information was developed (as discussed in Section 3.0). A vaporization rate in excess of about 11 $\mathrm{kg} \mathrm{s} \mathrm{s}^{-1}$, would result in fluidization and separation of the water from the molten uranium and cutoff of the heat transfer.

In the absence of venting an upper bound value for the subject pressure transient in connection with a postulated molten uranium metal-water interaction on the floor of the vacuum chamber can be estimated from

$$
\frac{d P}{d t}-\frac{R T}{V} \frac{d N}{d t}
$$

where $P(P a)$ - pressure in the vacuum chamber,

$t(s)$ - time,

$R\left(\mathrm{~J} \mathrm{~kg}^{-\operatorname{mol}} \mathrm{K}^{-1}\right)$ - gas constant $(8,314)$,

$I(K)$ - temperature $(-400 \mathrm{~K})$,

$V\left(\mathrm{~m}^{3}\right)$ - volume of vacuum chamber $\left(-1.28 \mathrm{~m}^{3}\right)$, and

$d N / d t\left(k g-m o l ~ s^{-1}\right)$ - steaming rate.

\footnotetext{
*Consideration of molten uranium-water interaction in the mold assembly
} leads to a steaming rate of $1.73 \mathrm{~kg} \mathrm{~s}$. 
Considering the interaction between molten uranium metal gives rise to a maximum steaming rate of about $11 \mathrm{~kg} \mathrm{~s}^{-1}\left(-.61 \mathrm{~kg}-\mathrm{mol} \mathrm{s} \mathrm{s}^{-1}\right)$, Equation $(6-1)$ can be integrated to give

$$
\begin{aligned}
P & =\frac{(8.314)(400)}{(1.28)}(.61) t \\
& =1.59 \cdot 10^{\circ} t
\end{aligned}
$$

Considering multiple fallures including loss of vacuum pressure prior to interaction (worst case), Equation (6-2) suggests that the design pressure of $15 \mathrm{psig}\left(-1.03 \cdot 10^{\mathrm{s}} \mathrm{Pa}\right)$ is reached in about $0.065 \mathrm{~s}$. In case of intact pressure boundary at the time of the molten uranium-water interaction, this time is increased to about $0.12 \mathrm{~s}$.

A sustained steaming rate of about $11 \mathrm{~kg} \mathrm{~s}^{-1}$ would result in complete absorption of the sensible heat from $100 \mathrm{~kg}$ of molten uranium in about 1 second. In the absence of venting and neglecting heat losses, Equation $(6.2)$ suggests an upper bound value of the pressure buildup of about 230 psi.

The necessary relief area, $A$, to safely vent the above steaming rate at the design pressure of $15 \mathrm{psig}$, can be estimated from

$$
w_{g}-\eta P_{B_{0}} A u_{s v}
$$

where $W_{B}\left(\mathrm{~kg} \mathrm{~s}^{-1}\right)$ is the steaming rate $\left(-11 \mathrm{~kg} \mathrm{~s}^{-1}\right), \eta$ is the critical pressure ratio $(-0.55), P_{B_{0}}$ is the steam density at the stagnation pres. sure $\left(-1.2 \mathrm{~kg} \mathrm{~m}^{-3}\right)$, and $u_{s v}$ is the sonic velocity of steam $\left(-500 \mathrm{~m} \mathrm{~s} \mathrm{~s}^{-1}\right)$. The above paraneter values lead to a rellef area requirement of about 0.033 $\mathrm{m}^{2}$ suggesting that two 6 -inch ports would be adequate without causing the pressure bufldup to exceed the design pressure of $15 \mathrm{psig}$.

It is noted that the venting arrangement and design (duct plus filter. etc.) external to the vacuum chamber is considered outside the scope of 
CODTU-93-0175

ENDT-93-006

Page 73

this study. For this purpose the arrangement should be designed to accommodate a conservative steaming rate of about $11 \mathrm{~kg} \mathrm{~s}^{-1}$.

Recalling that two 6 -inch fully open ports would be adequate to vent a steaming rate of about $11 \mathrm{~kg} \mathrm{~s}$ s $^{-1}$ without causing the pressure bulldup to exceed the design pressure of $15 \mathrm{psig}$ the above considerations suggest that the opening pressure for the rellef systex should be set near ambient pressure ( 1 psig) to allow for the maximum time $(-0.1$ s) to assure a fully open rellef system as the pressure approaches the design pressure of 15 psig. 


\subsection{OPERATIOALA COASIDGRATIONS}

With the operating philosophy to limit the potential for interactions between the molten uranium and water, there are several aspects of the system design which should be considered. These are listed below.

1. The system should not have power supplied to the furnace Induction colls to melt the uranium until the mold has been preheated to $800^{\circ} \mathrm{C}$. This preheated state would eliminate any trace water imbedded in the surface cavities within the mold and prevent localized interactions which would cause splattering and would prevent any unknown state of water resident in the mold which could promote explosive interactions.

2. If a coolant line on any of the three systems were to fail, there is no way to cause a substantial interaction between the water and the molten uranium if the melt is held within the crucible. Therefore, the operating philosophy should be to isolate the coolant flow to the induction coils and freeze the molten uranium within the crucible if there is any indication of an accident condition. The crucible cannot be harmed by turning off the power and stopping the coolant flow to the induction colls. In essence this implies that any condition which detects a loss of vacuum should shutdown the heating and cooling to the induction coils and allow the melt to freeze in the crucible.

3. Since the crucible and the mold are installed in the furnace as two separate entities, an interlock should be installed between the mold and the crucible which ensures that the desired relative position of these two elements is correct before power is applied to the mold which precedes the heating of the crucible. This interlock would minimize the chance of any spillage of molten uranium metal outside of the mold.

4. It is also recomended that manual shut-off valves be used to back up the automatic shut-off valves in the water circuits. This would assure isolation of the water coolant lines in any condition in which a loss of vacuun is experienced.

5. Maintaining the welt within the crucible would also minimize any potential for hydrogen generation as a result of meltwater interaction. 


\subsection{THMBYAL MRT-THROOGA COASTDERATIOAS}

The accumulation of the entire uranium inventory of about $100 \mathrm{~kg}$ on the vacuum chamber floor would not lead to nelt-through. *

The flat botton configuration and the low viscosity of the high temperature uraniun netal would result in quick spreading until the netal would freeze, resulting in a layer thickness of only about $0.007 \mathrm{~m}$.

Considering the large heat capacity associated with the l-inch stainless steel floor panel, we estimate an equilibrium temperature between the uranium metal and the steel plate of only about $250^{\circ} \mathrm{C}$, ignoring all other heat loss mechanisms.

\footnotetext{
*Assuming that the nolten uraniun metal at a temperature of $1500^{\circ} \mathrm{C}$ would come into direct contact with the cold stainless seel vacuum chamber floor, a contact temperature of about $750^{\circ} \mathrm{C}$ is estinated utilizing Equation (2-1), where stainless steel properties have been substituted for the water properties. Since this temperature is less than the eutectic temperature for the uraniun netal-steel system $\left(-800^{\circ} \mathrm{C}\right.$, Walker, et al., 1975), significant wall attack by eutectic formation can be ruled out. Substantial heat losses including quenching by the presence of water would further eliminate any concerns related to thermal melt-through.
} 


\subsection{SURARI ARD COACTUSIOAS}

Based upon the above considerations the following conclusions can be made :

- Damaging shock pressures resulting from possible explosive (steam) interaction between molten uranium $\left(-1500^{\circ} \mathrm{C}\right)$ and water can be ruled out due to lack of sufficient premixing between the molten metal and water. Given isolation of the cooling coll water in case of leakage the accumulated water levels within the uranium mold or on the floor of the vacuum furnace is iimited to about $0.06 \mathrm{~m}$ and $0.045 \mathrm{~m}$, respectively. The limited water layer suggests an acoustic relief time of about $10^{-5} \mathrm{~s}$, which is much less than the required fragmentation time of sbout $10^{-3} \mathrm{~s}$.

- Considering the shallow water pools, a conservative estimate of the steaming rate resulting from interaction between molten uranium jetting into the water located on the floor of the vacuum chamber is estimated to be about $11 \mathrm{~kg} \mathrm{~s}^{-1}$. A vaporization rate in excess of this magnitude, would result in fluldization of the water considering the entire floor area of $0.84 \mathrm{~m}^{2}$ is avallable for vapor escape (e.g., steaming rate in

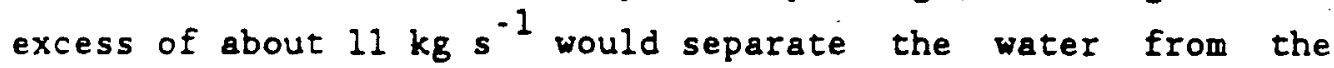
molten uranium resulting in cutoff of the heat transfer). The above steaming rate can be accomodated by 2 six-inch ports without causing the pressure buildup to exceed the design pressure of $15 \mathrm{psig}$.

It is noted that the venting arrangement and design (duct plus filter, etc.) external to the vacuum chamber is considered outside the scope of this study. For this purpose the arrangement should be designed to accommodate a steaming rate of about $11 \mathrm{~kg} \mathrm{~s} \mathrm{~s}^{-1}$. The relief system should be set near ambient pressure ( 1 psig) to allow for the maximum time $(-0.1$ s) to 
assure a fully open relief system as the pressure approaches the design pressure of $15 \mathrm{psig}$.

- Given multiple fallures (crucible cracking, coolant coll failure and vacuum chamber pressure fallure resulting in inflow of air), the possibility of $\mathrm{H}_{2}$-deflagration also needs to be evaluated. Consideration of chenical reaction between nolten uranium and water and formation of $\mathrm{H}_{2}$, indicates that oxidation of only about 0.33 of the available uranium $(-100 \mathrm{~kg})$ would satisfy the lower flamability linit ( 5 ) for $\mathrm{H}_{2}$ in dry air. This assumes that the $\mathrm{H}_{2}$ is accumulating in the vacuum chamber as $1 t$ is being formed, e.g., $\mathrm{H}_{2}$ is not escaping through the vents as it is being formed. However, it is well established that the presence of steam in excess of 50 volume percent eliminates deflagration altogether independent of $\mathrm{H}_{2}$ concentration.

Considerations of simultaneous heat transfer and resulting minimum steaming rates consistent with film bolling considerations as well as corresponding oxidation rates, suggest that the steaming rate would always exceed the 50 volume fraction required for eliminating the potential for damaging deflagrations.

In sumary, the evaluations suggest that the current vacuum chamber design given a design pressure of about $15 \mathrm{psig}$ and adequate control valves and timing for limiting water accumulation following cooling coil failures, would appear adequate. This conclusion is based on the availability of 2 six-inch ports to assure adequate relief in case of nolten uranium-water interactions. Finally, accumulation of the molten uranium ( $100 \mathrm{~kg}$ ) on the floor of the vacuun chamber poses no thermal threat, based on heat capacity considerations alone. 
$10-1$

CODTU-93-0175

ENDT-93-006

Page 78

\subsection{BDTHRTRGES}

Angelini, S., Yuen, W. W. and Theofanous, T. G., 1993, "Premixing-Related Behavior of Stean Explosions", paper presented at the CSNI FCI Specialist Meeting, Santa Barbara, CA.

Baker, Jr., L., 1983, "An Assessment of Existing Data on Zirconium Oxidation Under Hypothetical Accident Conditions in Light Water Reactors", Argonne National Laboratory Report.

Bang, K. H. and Corradini, M. L., 1991, "Vapor Explosions in a Stratified Geonetry", Nuclear Science and Engineering, 108, PP. 88-108.

Bankoff, S. G., 1978, "Vapor Explosions: A Critical Review", Proc. 6th Intl. Heat Transfer Conf., Vol. 6, pp. 355-360.

Benedick, W. B., et al., 1984, "Combustion of Hydrogen: Air Mixtures in the VGES Cylindrical Tank", NUREG/CR-3273, SAND83-1022.

Board, S. J. and Hall, R. W., 1976, "Recent Advances in Understanding Large Scale Vapor Explosions", Proc. 3rd Specialist Mtg. on Sodium/Fuel Interaction in Fast Reactors, PNC N251 76-12, Vol. 1, Tokyo, Japan, pp. $22-26$.

Epstein, M. and Fauske, H. K., 1989, "The Three Mile Island Unit 2 Core Relocation - Heat Transfer and Mechanism", Nuclear Technology, Vol. 87, 1021-1035.

Fauske \& Associates, Inc. (FAI), 1990a, "Steam Explosion Evaluation for the UDS Process Vesse1", Fauske \& Associates, Inc. Report No. FAI/90-14 submitted to Lawrence Livermore National Laboratory.

Fauske \& Associates, Inc. (FAI), 1990b, "Influence of Hydrogen Generation and Combustion", Fauske \& Associates, Inc. Report No. FAI/90-32 submitted to Lawrence Iivermore National Laboratory.

Fletcher, D. F. and Denhan, M. K., 1993, "Validation of the CHYMES Mixing Model", paper presented at the CSNI FCI Specialist Meeting, Santa Barbare, CA.

Glass, I. I., 1974, Sheck Waves and Kan, The University of Toronto Press.

Henry, R. E., et al., 1976, "Vapor Explosions and Simulant Fluids", Proc. Intl. Conf. on Fast Reactor Safety and Related Physics, ChIcago, IL. CONF-761001, P. 1862 .

Henry, R. E. and Fauske, H. K., 1979, "Nucleation Processes in Large Scale Vapor Explosions", Trans. ASME, Jr. of Heat Transfer, Vol. 101, Pp. $280-287$. 
Henry, R. E., Hammersley, R. J. and Klopp, G. T., 1991, "Direct Containment Heating Experinents in a Zion-Like Geometry", AIChE Symp. Serles, Heat Transfer, Minneapolis, 1991, 283, Vol. 87, Pp. 86-98.

Kutateladze, S. S., 1972, Elenents of Hydrodynamics of Gas-Liquid Systems", Fluid Mechanics - Soviet Research, Vol. 1, 4, p. 29.

Malinovic, B., Henry, R. E. and Sehgal, B. R., 1989, "Experiments Relating to Drywell Shell-Core Debris Interactions", Natl. Heat Transfer Conf., Philadelphia, PA, AIChE Symp. Series, Vol. 85, No. 269, Pp. 217-222.

Marshall, Jr., B. W., 1986, "Hydrogen:Alr:Steam Flamability Limits and Combustion Characteristics in the FITS Vessel", NUREG/CR-3468, SAND 84.0383 .

Mitche11, D. E. and Evans, N. A., 1986, "Steam Explosion Experiments at Interwediate Scale: FITSB Serles", NUREG/CR-3983, SAND 83-1057.

Tong, L. S., 1965, Bofling Heat Transfer in Two-Phase Flow, John Wiley \& Sons, Inc., New York.

Tsa1, S. S., et al., 1982, "Flame Temperature Criterla Tests", Proc. of the 2nd Intl. Conf. on the Impact of Hydrogen and Water Reactor Safety, Albuquerque, New Mexico.

Walker, C. M., et al., 1975, "U-Pu-Zr Metal Alloy: A Potential Fuel for IMFBRs", ANL-76-20, November.

Wang, S. K., Blomquist, C. A., Spencer, B. W., McUmber, I. M. and Schneider, J. P., 1989, "Experimental Study of the Fragmentation and Quench Behavior of Corium Melts in Water". Thermal-Hydraulics Division Trans. ANS Winter Meeting, San Francisco, CA, PP. 26-30. 
CODTU-93-0175

ENDT-93-006

Page 80

\section{Appendix B}

Closure on Fauske \& Associates, Inc.

Safety Analysis for the Uranium Vacuum Induction Furnace 
TO: John Sze

June 29, 1993

FROM: $\quad$ C. S. Landram

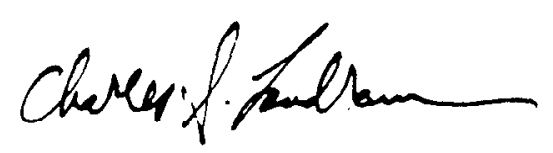

SUBJECT: Closure on Fauske \& Associates, Inc., Safety Analysis for the Uranium Vacuum Induction Furnace

Refs.

1. Fauske \& Associates, Inc. Safety Analysis, FAI/93-35, June 1993

2. Memo C. S. Landram to J. Sze, "Postulated Break of Ceramic Crucible and Liner for U-Casting Project," TF93-6, February 1, 1993.

The only major difference between the conclusions reached in the Fauske safety analysis (Ref. 1) and those in my work (Ref. 2) is the likelihood of a coolant water line rupture when significant quantities of molten uranium are available to contact the cooling coils following a ceramic crucible breakage. Ref. 1 concludes that the rupture is unlikely, while Ref. 2 concludes, to the contrary, that it is likely. This contradiction is addressed as issue 1 in the accompanying discussion. Because the consequences of a ruptured water line are shown in Ref. 1 to be nil with the engineered safety system design for the apparatus, the contradiction has no particular safety impact.

A minor second issue is in the margin of safety for a potential uranium melt through on the floor of the chamber. In the accompanying computation called issue 2, I show here that the chamber wall never comes close to a melt-through, while Ref. 1 shows that while the melt-through does not occur, the wall temperature nearly approaches the melt temperature. The discrepancy has no safety impact because both calculations show that a melt-through will not occur.

c: W. Comfort

L. Sedlacek 
CODTU-93-0175

ENDT-93-006

Page 82

\section{First Issue: Likelihood of a Coolant Coil Rupture (Section 2)}

As correctly stated in Ref. 1, the use of equation (2-1) applies prior to the thermal wave penetrating the copper wall thickness (see second paragraph of p. 2-11). This penetration occurs in about $.023 \mathrm{msec}$, after which the trivially thin cuust formed (about .002 inch) in the uranium melts almost instantaneously. The heat flux (Ref. 1, last paragraph of p. 2-11) would then not really be limited by crust conduction as stated in Ref. I (same paragraph). Rather, as computed in Ref. 2 (p.4), the copper wall will attain the coolant saturation temperature in about $5 \mathrm{msec}$, and the critical heat flux is exceeded some $1.2 \mathrm{msec}$ later $(6.2 \mathrm{msec}$ following the initial contact of uranium and copper tube). Once the critical heat flux is exceeded, the tubing will rupture. The footnote in Ref. 1 (p. 2-11) is very appropriate, and consequently, then, no credit for nucleate boiling should be taken, which then would mean tube rupture occurs sooner - in slightly more than $5 \mathrm{msec}$ (i.e., the additional time of $1.2 \mathrm{msec}$ for nucleate boiling can not be credited).

Because of the above analysis and previous actual observations that such coolant tubes do in fact rupture on contact with uranium, the statement on the middle of $p$. 2-10 (Ref. 1) is incorrect. It should read: 'However, the rupture of the mullite crucible and leakage of uranium onto the water cooled copper tubing used for the reduction coil [can likely] result in failure of the induction coil."

It should be recognized that the consequences of a ruptured water line were proven to be nil in Ref. 1. Thus, the fact that a cooling line rupture by melt through is more likely to occur has no impact with respect to a safety issue.

Second Issue: Thermal Floor Melt-Through (Section 8)

As posed on p. 8-1 of Ref. 1, a finite-thick $0.7 \mathrm{~cm}$ layer of uranium at $1500^{\circ} \mathrm{C}$ contacting a $2.54 \mathrm{~cm}$ thick stainless steel vacuum chamber floor at $20^{\circ} \mathrm{C}$ can not be analyzed using Equation (2-1) (with stainless steel properties substituted for copper). Eq. $(2-1)$ is valid only if the two thicknesses were semi-infinite, which of course they are not.

The equilibrium temperature of both finite layers of thickness $\delta$, each having thermal capacitance of $\rho c \delta$, is

$$
T\left({ }^{\circ} \mathrm{C}\right)=\frac{(\rho c \delta)_{n}(1500)+(\rho c \delta)_{m}(20)}{(\rho c \delta)^{*}+(\rho c \delta)_{\pi}}=230^{\circ} \mathrm{C}
$$

Because the stainless steel will rise to $230^{\circ} \mathrm{C}$, it is always well below the $800^{\circ} \mathrm{C}$ meltthrough temperature and well below the $750^{\circ} \mathrm{C}$ erroneously calculated on p. 8-1 of Ref. 1 . 